\title{
Finite Element Analysis and ANFIS investigation of seismic behavior of sandwich panels with different concrete material in two story steel building
}

\author{
Faezeh Jafari \\ Department of Civil Engineering, Malayer University, Malayer 65719-95863, Iran \\ faeze_jafari666@yahoo.com \\ Baitollah Badarloo \\ Department of Civil Engineering, Qom University of Technology (QUT), Qom 37181-46645, Iran
}

\begin{abstract}
This study aimed to apply sandwich panel in a two-story steel building to improve its behavior. Sandwich concrete panels consist of three basic components including wires, insulating layer and concrete cover. This research studied the behavior of sandwich panels by changing the Young's modulus of the concrete with Finite Element Method and evaluated the displacement, acceleration, and panel stresses. According to the results, increasing the Young's modulus of the concrete, the frame seismic behavior was improved. Using sandwich panels instead of conventional brick increased the building resistance against seismic load while decreasing the structure drift and acceleration. Increasing the Young's modulus of the shotcrete layer enhanced the behavior of the seismic panel. In addition, the results showed that the two-story building, which comprised of sandwich panels, had an appropriate performance against the seismic load. Ultimately, ANFIS was used to predict the response of the building under seismic loads. The effects of some variables such as Young's modulus of concrete, variations on the elevation and panel's number on displacement and acceleration have been presented.
\end{abstract}

KEYwORD. Sandwich Panel; Finite Element Method; Young's Modulus; Seismic Load; ANFIS.

\section{OPEN ACCESS}

Citation: Jafari, F, Badarloo, B, Finite Element Analysis and ANFIS investigation of seismic behavior of sandwich panels with different concrete material in two story steel building, Frattura ed Integrità Strutturale, 50 (2019) 209-230.

Received: 18.04 .2019

Accepted: 12.08 .2019

Published: 01.10.2019

Copyright: (c) 2019 This is an open access article under the terms of the CC-BY 4.0, which permits unrestricted use, distribution, and reproduction in any medium, provided the original author and source are credited.

\section{INTRODUCTION}

$\mathrm{T}$ he system components were sandwich panels comprised of two welded steel meshes on the two sides and an insulating polystyrene layer in the middle, in which the two mesh layers were linked through diagonal wires constructing a spatial mesh. After installation in the execution place, these panels were sprayed with concrete on the sides and finally a united structure of reinforced concrete was produced. Therefore, the issue of spraying concrete 
shotcrete was important as one of the important parts of sandwich panel. Besides, applied shotcrete with additives like micro-silica in the sys-tem that was comprised of small stone material improved the panel behavior. For this purpose, significant experimental and numerical researches were made for improving shotcrete behavior. Applying shotcrete in different structures for improving their performance has an old history. For the first time in 1914, shotcrete was used in an experimental mine in the USA [1]. After that, this system was used for covering stone surfaces and protecting them against weathering and in some cases as a temporary protection system. Owing to the fact that shotcrete was obtained as sheets of the bedrock, it was not considered as a fundamental protection system. After three decades, considerable progress has been made in mixing methods, additive material, machinery, and spray methods that led to the improvement of FRS performance in the economic sector and its mechanical properties and that is why has been used extensively all over the world [2]. Hence, using additive clearly improved the shotcrete performance and determining the range of Young's modulus of shotcrete with additive and studying the panel behavior in different Young's modulus is a new subject and necessary for sandwich panel. In addition, finding a way for enhancing the sandwich panel behavior and its mechanical properties of sandwich panel parts such as wire-insulting layer and concrete have been recently the subject of numerous experimental and numerical FEM studies. For example, Metelli et al in 2011 investigated the numerical behavior of concrete sandwich panels with glass fiber-composite connectors with the aim of focusing on the stresses and deformations caused by dead load, thermal actions and shrinkage [3]. In 2014, Palermo et al. investigated sandwich panels behavior in a three-story concrete frame with thin sandwich panel walls. It should be noted that the panel behavior has been studied separately in most previous cases without focusing on the performance in the building [4]. In 2016, Yokozeki et al. studied the vacuum-assisted resin transfer molding as a way for analyzing the effects of core machining configuration on the interfacial deboning toughness of foam core sandwich panels fabricated [5]. Hashemi et al. investigated the behavior using a concrete sandwich panel as an infill wall on the in-plane behavior of steel frames. The result of study showed that the interaction between the concrete sandwich panel and the steel frame in specimen IFM increased the initial stiffness, lateral strength, energy dissipation, and the equivalent viscous damping ratio of the system compared with the bare frame [6]. Heywood et al. reviewed the results of 12 single-spans. In this study,11 double-span bending tests conducted on profiled composite panels with polyisocyanurate cores sandwiched between light-gauge steel faces [7]. Applying FEM method for analyzing sandwich panel under the earthquake load has been observed in some earlier researches, for example Rezayifar et al. in 2007 studied one story sandwich panel building using ANSIS, and also laboratory test. According to this study result, ANSIS can correctly predict panel displacement and acceleration [8]. Palermo et al. studied the thin RC sandwich walls behavior under the seismic load in laboratory. This research introduces concrete damage mode, which has been validated throughout experimental tests. Force-displacement response and the damage progression were attained during experimental test was accomplished in different models [9].

Employing sandwich panel under the earthquake load and elaborating on the behavior of the panel in the steel building with Finite Element Method (FEM) and ANFIS is an important goal, which has been never achieved in the past. To this aim, ANFIS has been used as a neural network in this research. Neural network as practical method has been used to predict the earthquake load and performance of the structure in some research for analyzing laboratory and numerical research. Lee predicted damage localization for bridges using the probabilistic neural network, modal parameters, and ambient vibration data as the feature vectors for probabilistic neural networks [10].

Arslan used regression analyses (Multi-linear and Nonlinear Regression (MLR, NLR)) and 11 various Artificial Neural Networks (ANN) methods to predict curvature and displacement ductility in reinforced concrete buildings and some parameters which influence the curvature and displacement ductility values [11]. Bagheri et al. investigated the new method for the estimation of strong ground motion with the colonial competitive algorithm; the result of the study led to predicting horizontal peak ground acceleration and spectral acceleration. The colonial competitive algorithm can be considered as a powerful and reliable tool for solving complex optimization problems [12]. Pang et al. in 2014 studied the ANN in order to estimate the fragility analysis of highway bridges. This research result indicated that ANN method could predict fragility accurate curve with optimizes time in cooperation. Furthermore, the sensitivity analyses demonstrated that the materials and geometric uncertainty play significant role in fragility curves increasing [13].

Kalman Šipoš et al. used ANN and BA methods in order to predict the multi-story frames seismic response. These methods were accomplished on laboratory data of one-story of (RC) frames with masonry in-fills. This research indicates that these two methods are considered as acceptable methods for base shear prediction, and also story drift of in-filled frame behavior prediction under seismic load [14].

Gholizadeh et al. studied the optimal design method in order to predict the structures performance in the earth quake load. The numerical results display the employing ANN efficiency to estimate the optimal weight of two structures under the earthquake [15].

Badarloo et al studied the effect of position and number of openings on the performance of composite steel shear walls, 
This research contains various models such as shear wall with openings close to the beam/column, horizontal/vertical openings and distributing opening. Push over method was employed in order to obtain shear wall performance (capacity, stress and displacement), then ANN and fitness function tools were employed to obtain neural network models for shear wall [16].

Applying additives for conventional concrete has been the subject of much research. The performance of sandwich panel has been studied in different experimental previous research, but there are few numerical investigations on improving the sandwich panel behavior under the seismic load and how changing the shotcrete Young's modulus affects the behavior of the building. The present research studies the effects of the Young's modulus on performance of a panel against earthquake load in a two-story building. Therefore, first, using the data from the literature on shotcrete with Silica additive, the range of Young's modulus has been chosen based on this research, thus, the compressive strength, Young's modulus and the density of the shotcrete are obtained and also, the properties of other materials like steel wires, insulating panel and concrete layers are introduced into the soft-ware. After this process, the panel performance against loading is evaluated by changing the amount of Young's modulus in different panels and the results were analyzed. Besides, the effects of increasing the panels' number and height on the frame performance are another aim of the present study. Using ANFIS to predict the numerical FEM result of sandwich panel is another new issue, which will be discussed in the concluding part of this study. Applying ANFIS as the neural network to interpret ABAQUS results and investigate the capability of this method to predict FEM out-puts are the ultimate goals.

\section{METHOD}

\section{$\mathrm{T}$} 1 his research investigates the effects of additive on shotcrete concrete sandwich panel (that leads to an increase in concrete Young's modulus) and sandwich panels performance in a large (building frame) and small area (concrete layer, sandwich panel), respectively. Here, for obtaining the Young's modulus, the data reported by Wolsiefer [2] and Rezayifar was used. For this purpose, the Young's modulus between (15 GPa to $30 \mathrm{GPa}$ ) are considered and different points in different areas of the frame are chosen. The software ABAQUS is used as the analysis tool [17]. A tie is used to paste the insulating layers to concrete according to the proposal of composite material; moreover, a nonlinear dynamic analysis is applied. Electro acceleration is imputed in the support place in X and Y direction. On the left side of the frame, two oblique panels and on the right side, three panels are applied. The panel making procedure by ABAQUS was proposed by Gara in 2012 and panel-making processes are similar [8, 18]. Wire mesh is embedded in concrete layers and the walls are connected to the column. Fig. 1 presents the schematics of the modeled panel.

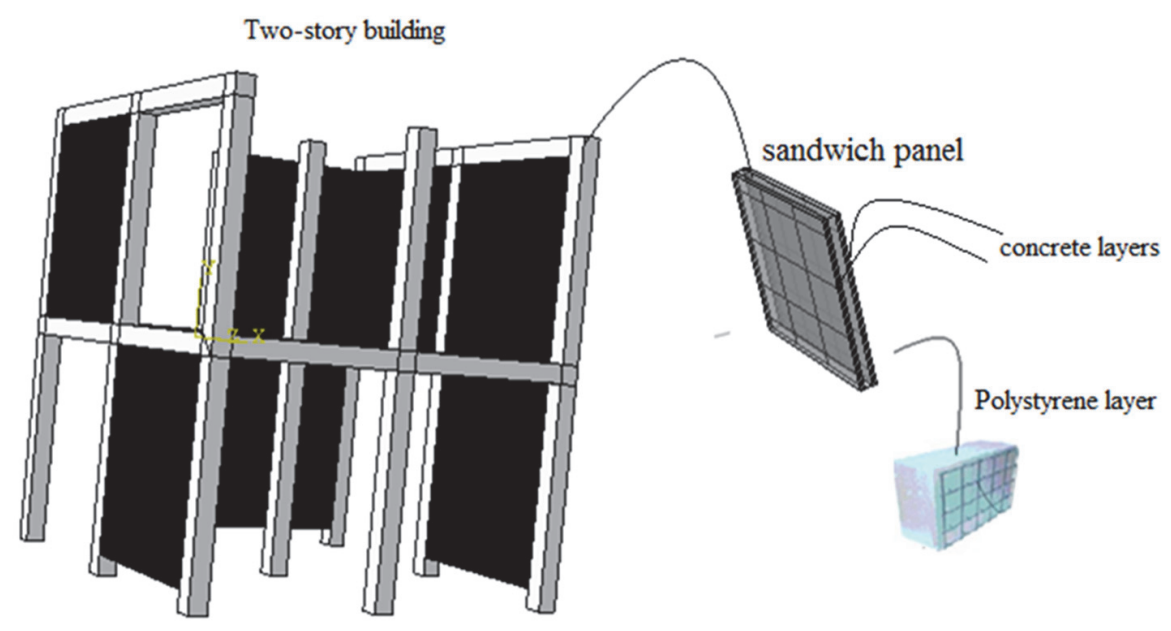

Figure 1: Schematics of the model in ABAQUS

The acceleration and displacement are calculated and depicted in the diagram for all the mentioned concretes.

The present research has the following main steps:

$\checkmark$ An experimental and numerical paper from science direct journal has been chosen as the reference for verification. This paper is an FEM and experimental study on sandwich panel for earthquake load. Therefore, 
this article is of high relevance and very similar to the present work. In other words, it is the only article, which has the most common ground with our field of study. ABAQUS has been used for modeling in this paper. Then, the results of the present study were compared with those of Rezayifar and are in close agreement with the study by Rezayifar [8]. Next, EL- Centro as one of acceleration histories, which has existed in the reference research, was chosen for the present paper. Ultimately, Matlab analyses were compared with FEM analyses and the results showed that Matlab could predict FEM result in the best way, because the results of the two methods are close to each other. ANFIS results were verified with ABAQUS and experimental research using neural network for estimating the maximum displacement and acceleration value, which were obtained by ABAQUS.

$\checkmark$ The effect of the panels' number on the frame seismic behavior is investigated. In different frames of the building, the frame seismic performance has been evaluated by applying two-three panels.

$\checkmark$ The shotcrete material is varied and the effect of Young's modulus in shotcrete is investigated. First, the change in the frame shape is discussed for the conventional concrete and then by changing the shotcrete material, the frame performance is studied.

$\checkmark$ The height of the point is varied and the relationship between Young's modulus and height on the displacement and acceleration of these points is elaborated.

\section{ABAQUS VERIFICATION}

I n 2000, Rezayifar et al [8] studied the dynamic behavior of 3D sandwich panels in a single story system, for which shaking table testing was used and the 3D-panel wall was modeled using Ansys. In this study, El-Centro (Imperial Valley Station - 1940) acceleration was chosen as a lateral load in X and Y direction and the result of FEM analyses were compared with the experimental work. In this work, concrete sandwich panels were used for making 3D-panel house. The panel dimension was 3.350* 3.30. In addition, support conditions were assumed in the bottom of the panels. The building plan as well as its height and details are summarized in the reference paper, which has been applied for modeling the building in the present research. The main materials (steel bar, concrete panel sand polystyrene) were assumed according to the specifications reported by Rezayifar [8]. Rezayifar et al applied various accelerations on the sandwich panels, but in this research, only EL- Centro acceleration was used as a seismic load.

The research conducted by Rezayifar et al is the only comprehensive study, which has worked on sandwich panel house and evaluated its performance under seismic load. Displacement and acceleration were measured in some specific points in the experimental and FEM model in two directions. According to Rezayifar paper, DIS03 is a point located on the top of the northern wall and is used for measuring displacement in the X direction, while DIS01 is located on the western wall and is used to measure displacement in the $\mathrm{Y}$ direction. Fig. 2 illustrates the acceleration in both directions (X and $\mathrm{Y})$. These two points have been used to validate this study, where the building has been modeled in ABAQUS software and the displacement has been obtained in the two directions. The results revealed a good agreement between the present research and the experimental work of Rezayifar. Fig. 2 presents the ground acceleration records applied into the structure and Fig. 3 presents the structure mesh of one storey sandwich panel. Fig. 4 compares displacements in this study in both directions with Rezayifar.
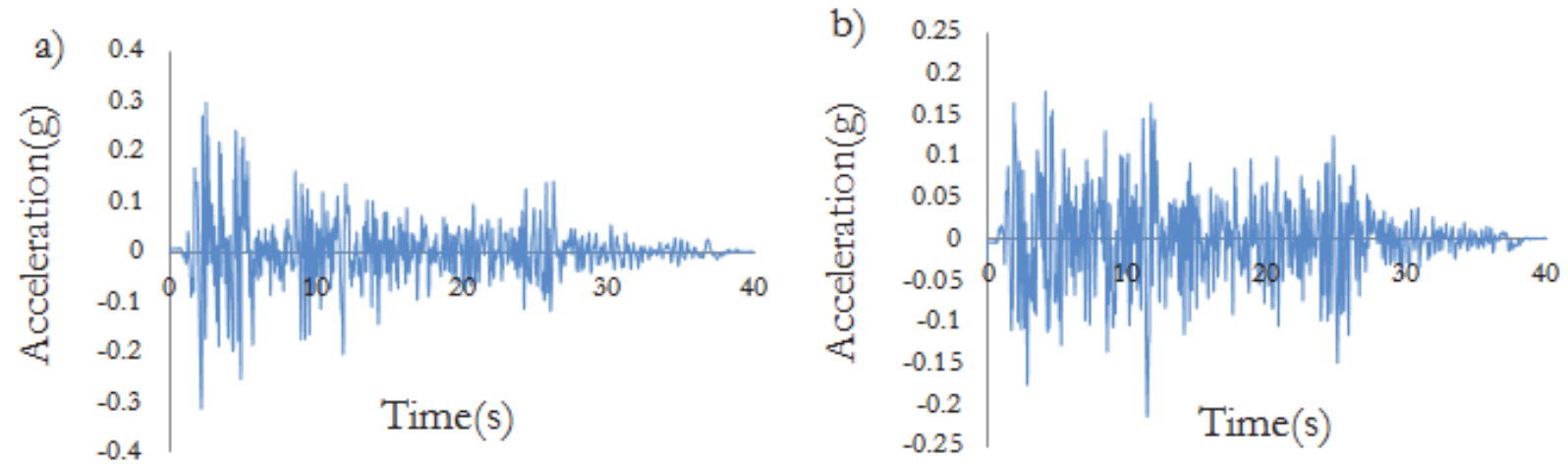

Figure 2: Acceleration time history of El Centro -1940 record (a) x direction, b) y direction) [18]. 

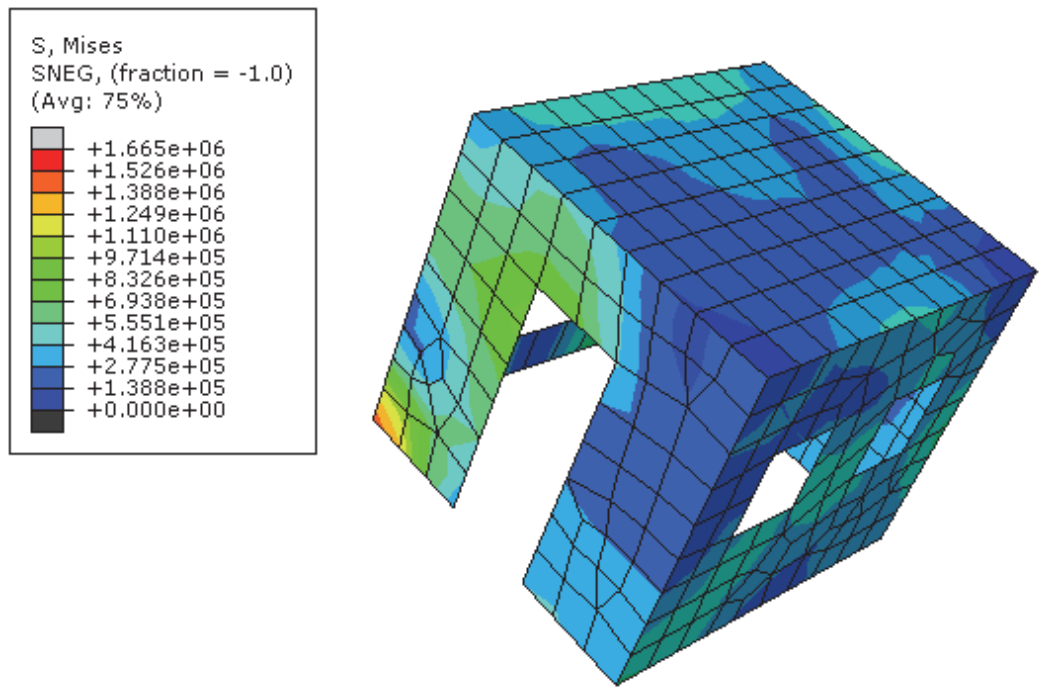

Figure 3: The stress result for verification model.
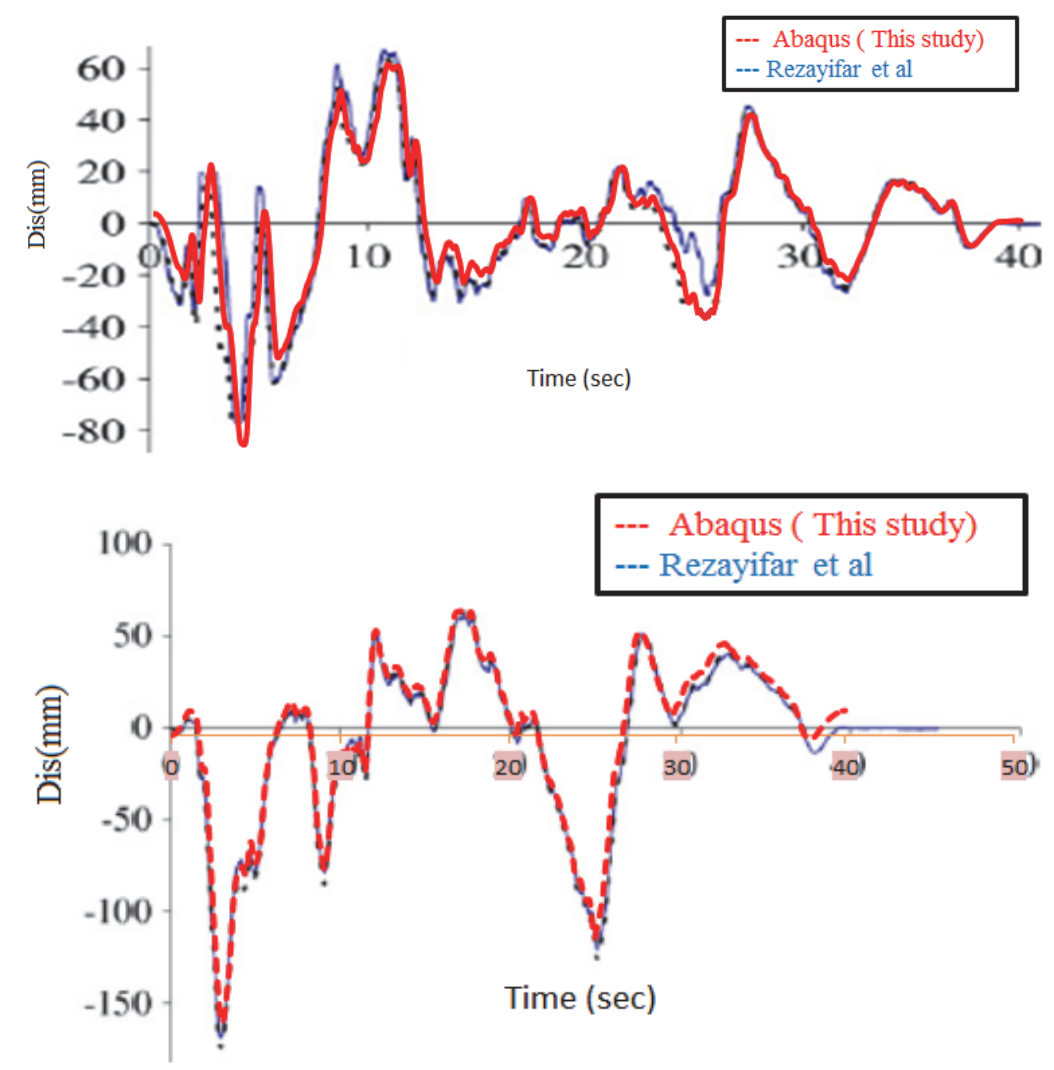

Figure 4: Time history of top displacement in $\mathrm{X}$ and $\mathrm{Y}$ directions for El Centro record

\section{ABAQUS MODELS AND MATERIAL}

\section{Determining the range of Young's modulus and stress - strain curve}

ased on the stress-strain diagram, the first section of the curve is a straight or almost straight line for which the expression of Young's modulus is used. Young's modulus of concrete which increases with increasing compressive strength is affected significantly by the Young's modulus of aggregate and its volumetric ratio in the concrete. Some 
regulations express this effect by the Young's modulus, as a function of concrete density [19-21]. With an identified aggregate type, typically the direct relationship has been observed between the compressive strength and elastic modulus. Consequently, the Young's modulus confirms the general conclusions drawn above on the curing conditions, water/cement ratio, and etc. influence on the compressive strength.

Young's modulus, compressive strength, and stress-strain curve for conventional concrete in every age can be calculated based on compressive strength with different equations, which has been mentioned in the following references [21-23]. Some researcher use experimental test to evaluate the strength of shotcrete for example: John Wolsiefer, pointing to the fact that for the first time Silica was used in the nineteenth century in Norway, investigated different methods of adding Silica to concrete and obtained compressive strength [2]. Different Silica products are added to concrete in this research.

Rezayifar used two types of concrete for making concrete sandwich building; these concretes were prepared with Portland cement (II), and $\mathrm{W} / \mathrm{C}$ is assumed 0.45 for all the samples. Compressive tests were done for standard cubes samples and shotcrete cores used based on ACI and ASTM specifications.

The concrete specifications used in Rezayifar research are close to those of Velsfir samples. In fact, Velsfir considered shotcrete compressive strength ranging from $15 \mathrm{MPa}$ to $60 \mathrm{MPa}$ and the relationship between the compressive strength of the concrete and the Young's modulus is reported in the laboratory references [2]. In the present study, for the first and third samples, the concrete specimens constructed by Rezayifar were used, and the Young's modulus and compressive strength for the concrete layer were considered the same as Rezayifar's research. Because the purpose of this study is to consider a wide range of concrete Young's modulus, the authors tried for the third sample to get help from the high values referred to by Velsfir. After determining the compressive strength, using the three experimental references, and suggesting the relationship between the compressive strength, the Young's modulus was estimated for sample three. Thus, it was tried that an acceptable wide range in the recommended values of laboratory references is selected for the concrete layer so that the upper and lower limits of the Young's modulus could be included. Due to this purpose, each of these references suggested an equation to obtain the relationship between $f_{c}$ and $\mathrm{E}$ [21-25]. In this paper, all proposed equations in the experimental references were used to obtain the value of $f_{c}$ and then their average was extracted. Finally, the approximate Young's modulus has been reported based on the work of John Wolsiefer and Rezayifar. The values are presented in Tab. 1.

\begin{tabular}{|c|c|c|c|c|c|c|}
\hline \multicolumn{7}{|c|}{ Concrete } \\
\hline Samples & $\begin{array}{l}\text { Elastic } \\
\text { module } \\
(\mathrm{GPa})\end{array}$ & $\begin{array}{l}\text { Poisson } \\
\text { ratio }\end{array}$ & $\begin{array}{l}\text { Dimension } \\
\quad(\mathrm{m})\end{array}$ & $\begin{array}{l}\text { Density } \\
\left(\mathrm{kg} / \mathrm{m}^{3}\right)\end{array}$ & $\begin{array}{l}\text { Compressive } \\
\text { Strength } \\
(\mathrm{MPa})\end{array}$ & $\begin{array}{c}\text { Tensile } \\
\text { Strength } \\
\text { (MPa) }\end{array}$ \\
\hline Sample1 (24 hours) [8-2]. & 15 & 0.3 & $4.2 * 3.6 * 0.1$ & 2300 & 28.6 & 2.8 \\
\hline Sample 2(Middle) [8-2]. & 24 & 0.3 & $4.2 * 3.6 * 0.1$ & 2300 & 32.1 & 3 \\
\hline Sample 3(63 days) [2]. & 30 & 0.3 & $4.2 * 3.6 * 0.1$ & 2300 & 63 & 4.7 \\
\hline \multicolumn{7}{|c|}{ Steel (wire and Frame) } \\
\hline Type & $\begin{array}{l}\text { Elastic } \\
\text { module } \\
(\mathrm{GPa})\end{array}$ & $\begin{array}{l}\text { Poisson } \\
\text { ratio }\end{array}$ & $\begin{array}{l}\text { Dimension } \\
\quad(\mathrm{m})\end{array}$ & $\begin{array}{l}\text { Density } \\
\left(\mathrm{kg} / \mathrm{m}^{3}\right)\end{array}$ & \multicolumn{2}{|c|}{ Yield stress (MPa) } \\
\hline Steel Wire [8]. & 200 & 0.3 & $\emptyset_{20}$ & 7870 & \multicolumn{2}{|c|}{470} \\
\hline Frame (Solid) [8]. & 200 & 0.3 & ---- & 7870 & \multicolumn{2}{|c|}{470} \\
\hline \multicolumn{7}{|c|}{ Insulating layer } \\
\hline Type & $\begin{array}{l}\text { Elastic } \\
\text { module } \\
(\mathrm{GPa})\end{array}$ & $\begin{array}{l}\text { Poisson } \\
\text { ratio }\end{array}$ & $\begin{array}{l}\text { Dimension } \\
\quad(\mathrm{m})\end{array}$ & $\begin{array}{l}\text { Density } \\
\left(\mathrm{kg} / \mathrm{m}^{3}\right)\end{array}$ & $\begin{array}{l}\text { Compressive } \\
\text { Strength } \\
(\mathrm{MPa})\end{array}$ & $\begin{array}{l}\text { shear } \\
\text { Strength } \\
(\mathrm{MPa})\end{array}$ \\
\hline (Solid) [26-27]. & 0.0030 & 0.41 & $4.2 * 3.6 * 0.2$ & 32 & 0.172 & 0.152 \\
\hline
\end{tabular}

Table 1: Specifications of the modeled building components in the ABAQUS. 


\section{MODELS IN THE BUILDING WITH ABAQUS}

\section{Part and material}

he considered building was of steel and had two stories. The peripheral panels comprised of two shotcrete concrete layers and an insulating middle layer, for which the physical properties are presented in Tab. 1. This study aimed to analyze the sandwich panel dynamic seismic behavior. For this purpose, the acceleration was entered into support conditions in $\mathrm{X}$ and $\mathrm{Y}$ direction and the results showed that all of the samples could completely withstand all the loading cycles. Fig. 5 presents the ground acceleration records applied into the structure and Fig. 5 presents the structure mesh and the columns coordinate.

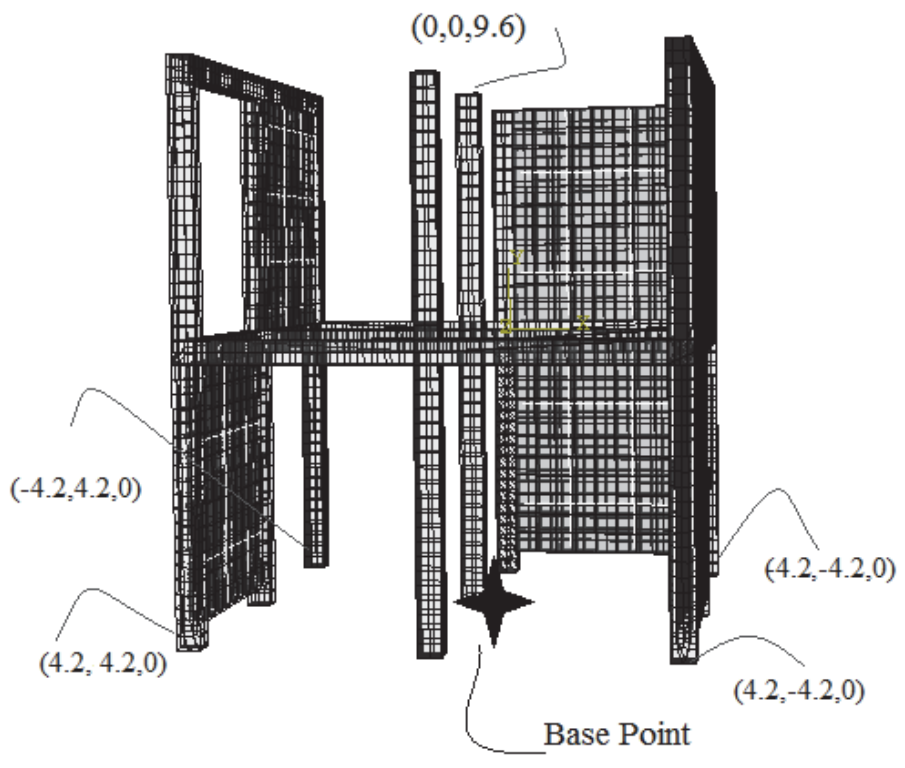

Figure 5: the structure mesh and location of the points.

For all steel frames, concrete panel, insulting layers were modeled using element type of Solid Homogeneous (S4R), and wire was modeled using wire element (Beam type).The Young's modulus and Poisson's ratio for steel, polystyrene, concrete and brick materials, with respect to its characteristic strength, were assumed according experimental research and these values was entered into ABAQUS (property panel).

Concrete layers were used for the walls, which was connected to the insulting layers. Stress-strain curve was used to show material's plastic behavior. The compressive strength of the concrete was 28-63 MPa and tensile strength is 2.8-4.7 MPa. Concrete damage plasticity was used to model plasticity behavior of concrete. In this section, stress-strain curve for compressive and tensile behavior of concrete was obtained according to Hsu et al [21].

\section{Connections and boundary condition}

Concrete panels were used as out layers panels, which were connected to the polystyrene plate. In order to this aim, using Tie connection in constrain part, according to the previous researchers for composite material [17-18]. After joining these two panels, ABAQUS assume them as composite pieces which have both features (concrete and polystyrene).

Using sandwich panel makes acceleration more uniform in both building side. For instance, the acceleration of brick panel in the right side is 1.47 more than the left side; however, by the use of sandwich panel this ratio is reaching to 0.7. Fig. 6a displays the dimension of main steel frame, the height of frame is 8.9, and the width is equal to 6.4. Fig. 6b shows the sandwich panel dimension, which was perched in the steel frame. Fig.6c shows steel mesh dimension, which was embalmed in the concrete part. Different parts of steel building were merged together in the right place. After that, insulting layers merge to steel frame and property panel was checked in order to allocate the steel to frame, and also polystyrene to insulting layers. Finally, the concrete panels were paste to the insulting layers by the use of Tie connection. As a result each element plays a special role with maintaining own characteristic in the frame. 

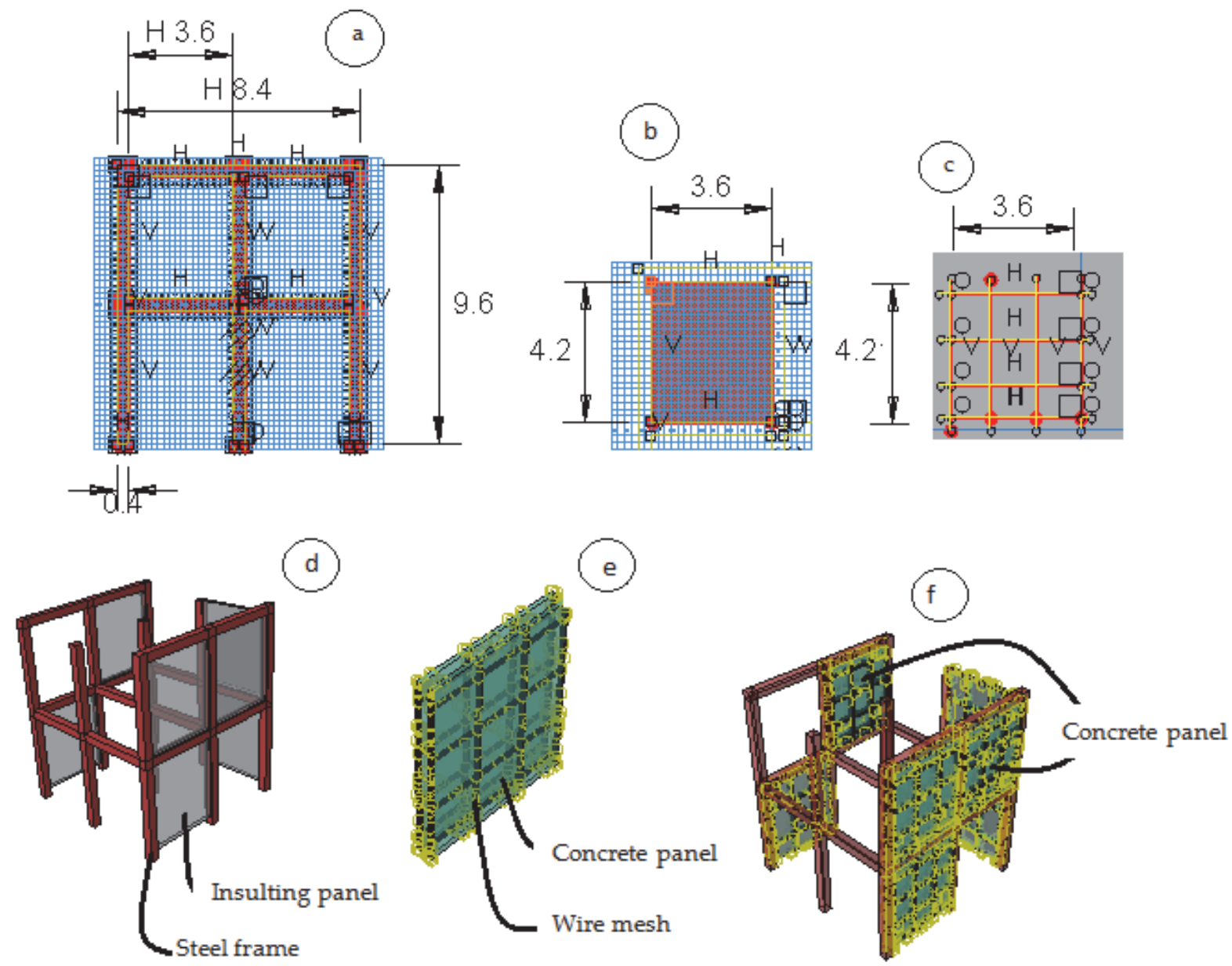

Figure 6: Building and panel details (steel frame dimension, b) concrete and insulting layers, c) steel mesh, d) steel building with insulting layers, e) concrete and steel mesh, f) steel building with sandwich panels.

The characteristic of steel was entered into ABAQUS and stress-strain curve was used to show steel plastic behavior. Concrete damage plasticity was used to model a concrete plate. Here, a stress-strain curve for compressive and tensile behavior of concrete was calculated [24-25]. This model was also able to define the failure behavior of the concrete in the software.

\section{Meshing part}

In this part, the structured meshing technique was employed for meshing all part. By this technique, ABAQUS /CAE choose square mesh regularly for solid part geometry. The advantage of this method is that this type of mesh creates small boundaries to the mesh seeding to make sure that the opposite sides of the rectangular parts have the equal numbers of seeds. In this study, the frame was cut to different rectangular parts; the approximately global size of meshing was chosen 0.23 . Since smaller mesh sizes were also examined in this structure, the obtained results were not affected by mesh downscaling.

\section{Outputpart}

The measure of displacement was computed in different points of the building and compared for different samples. For investigating the effect of sandwich panel behavior on the steel building frames, different numbers of panels in each frame were applied (three panels on the right side and two on the left) and displacement and acceleration at various points of the frame were evaluated. 8 points were considered as follows, points 1-2 in concrete layers, points 3-4 in upper points of steel frame columns, points 5-6 in panels and points 7-8 in the support conditions. The coordinate of the points are presented in Tab. 2. In this step, step panel and set tools were employed to obtain output value (acceleration, stress, displacement and base shear). 


\begin{tabular}{ccccccccc}
\hline \multicolumn{7}{c}{ Point } \\
$\begin{array}{c}\text { Points' } \\
\text { number }\end{array}$ & $\mathbf{1}$ & $\mathbf{2}$ & $\mathbf{3}$ & $\mathbf{4}$ & $\mathbf{5}$ & $\mathbf{6}$ & $\mathbf{7}$ & $\mathbf{8}$ \\
Location & Concrete layers & Steel frame & Insulting layers & Base points \\
X & -0.84 & -0.84 & +4.2 & +4.2 & 2.73 & 2.73 & +4.2 & +4.2 \\
Y & 4.2 & -4.2 & +4.2 & -4.2 & +4.1 & -4.1 & +4.2 & -4.2 \\
Z & 8.7 & 8.7 & 9.6 & 9.6 & 3.68 & 3.68 & 0 & 0 \\
\hline
\end{tabular}

Table 2: The coordinate of the points

\section{Number of models}

Finally in this research, three models of sandwich panels with respect to the materials (concrete, polystyrene, and steel wire) in a steel building were modeled and were compared with the brick panel. The general purpose was to study the behavior of the building against the imposed acceleration.

\section{Boundary condition and seismic load pattern}

This paper is an FEM and experimental study on sandwich panel for earthquake load. Therefore, Rezayifar's research in 2007, is of high relevance and very similar to the present work. In other words, it is the only article, which has the most common ground with our field of study (sandwich panel and seismic load). Boundary load condition and acceleration time history of El-Centro have been assumed according to Rezayifar's experimental research [8]. Electro acceleration is imputed in the support places in $\mathrm{X}$ and $\mathrm{Y}$ direction. Then, the results of the present study were compared with those of Rezayifar and are in close agreement with the study by Rezayifar [8].

\section{RESUlTS}

\section{The results in the $X$ direction}

I ncreasing the Young's modulus decreased the frame displacement in different points. The panel's number on the right side was different from that on the left side. According to the results for points 1 and 3 of the frame right side, the displacement measure on the right side was more than the left side due to the greater mass (three panels). Fig. 7 to 18 illustrate the building displacement and acceleration measure at various points of the concrete panel and the frame. It is believed that the material density and height affects the frame displacement. Points on the columns have the greatest measure of displacement and acceleration, followed by the points on the concrete layers, and the least measure of displacement and acceleration is of the insulting layers.

Analysis of the overall results of sandwich panels in the frames of other concrete and brick material is presented in diagrams 18 to 24 . As it is illustrated in the Figures, applying sandwich panels decreased the frame weight, acceleration and its displacement and hence improved its performance. In the following, the displacement and acceleration measure in different points of the building (panels, concrete layers and column edges) is illustrated for the right and left sides of the building.

Fig. 7 and 8 illustrates the maximum value for stress, acceleration, and displacement in the building as an example of a building built with sandwich panel.

Fig. 7 presents the displacement and acceleration in the concrete building for 24 hours sample; the displacements and accelerations on 24 hours samples are higher than all samples.

Fig. 8 depicts Von-Misses stress in the layers of concrete for 24 hours sample; the stress on 24 hours samples is higher than all samples as shown here. Comparing the results indicated that building sandwich panels with 24-day concrete samples causes an increment in moving frame, imposed acceleration, and stress.

Fig. 9a presents the concrete displacement on the 24-hour concrete layers and brick material. Comparing the results of shotcrete concrete with brick material and considering the difference in the displacement measures shows that the displacement could be reduced by 1.21 times at critical points and the displacement was decreased during these times. It could be concluded that applying the concrete with high Young's modulus (shotcrete and Silica) is efficient in improving the behavior of concrete panels, especially the concrete layers as it is shown clearly; when the time passes 11, all of the 
displacement recorded for different times in brick panel are higher than the sandwich panel. Likewise, Fig. 9b indicates that the maximum base shear belongs to the brick material and the lowest value is associated with the 24-hour sample.

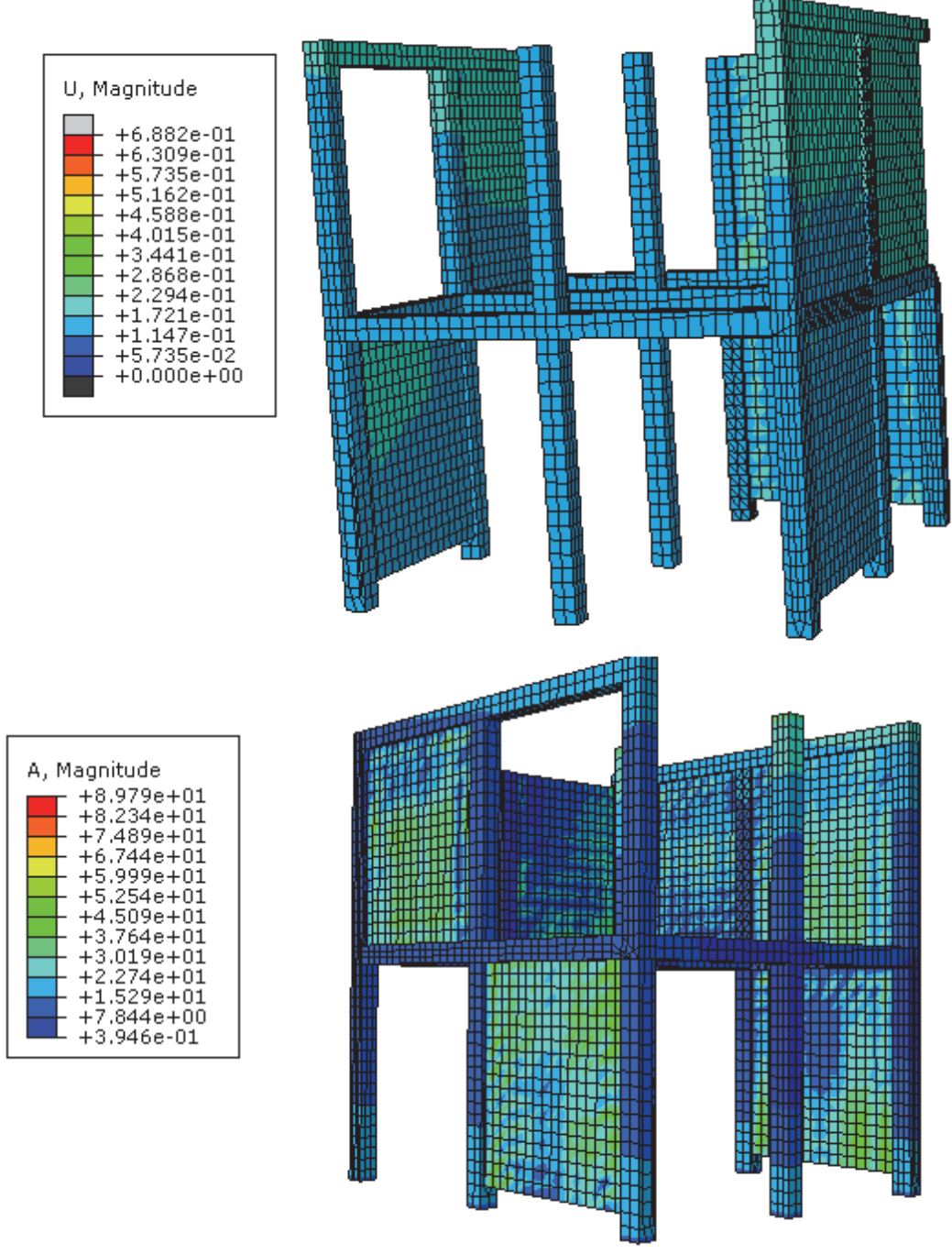

Figure 7: The displacement and acceleration response for building (sample 1).
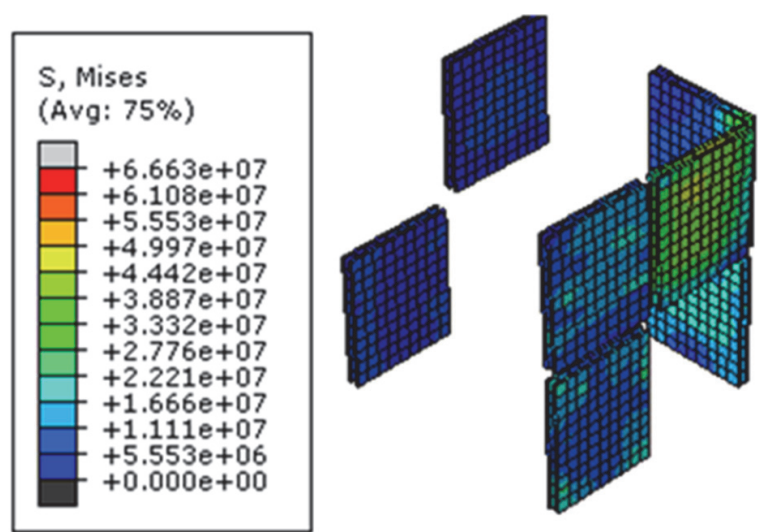

Figure 8: The effective stress on the concrete layer (sample 1). 

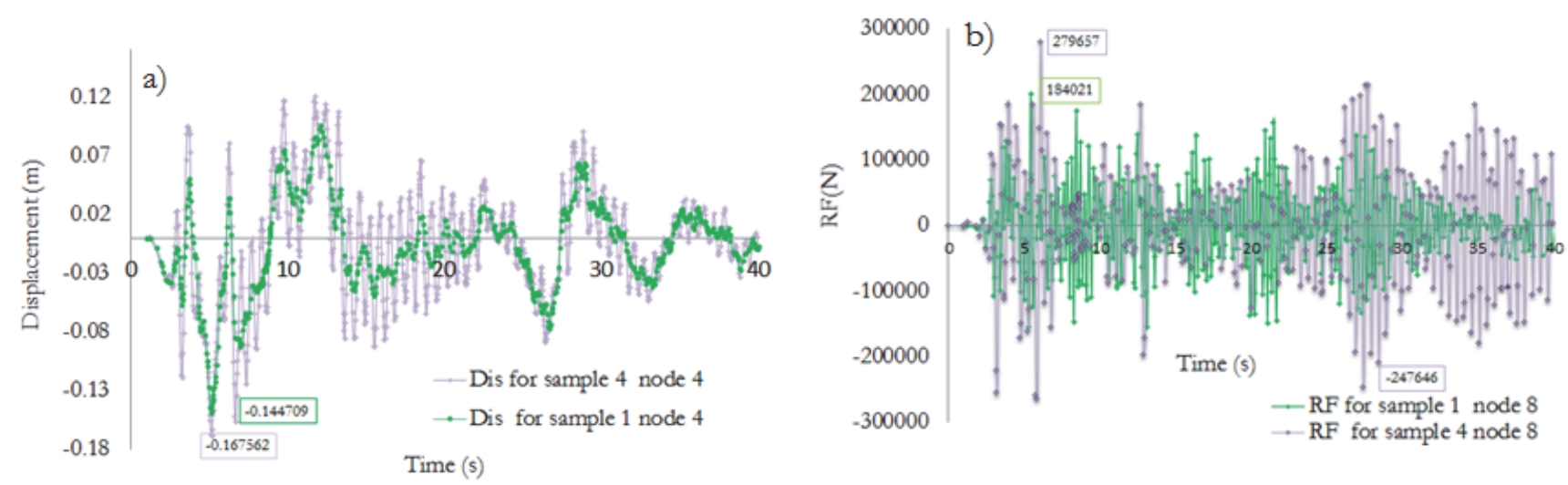

Figure 9: The frame displacement and base shear (brick and concrete)

Fig. 10 presents the displacement measure in concrete layers on the right and left sides of the building for different samples. Three panels were applied on the right side and two on the left. Point 1 is in the panel concrete layer on the right side and point 2 of the left side. For all the accelerations, the displacement measure on the right side of the building is 1.18 times more than that on the left on the maximum value. Analysis of the results of shotcrete with different Young's modulus shows that the most displacement measure belongs to the sample 1. The result shows that lower Young's modulus causes more displacement measure.
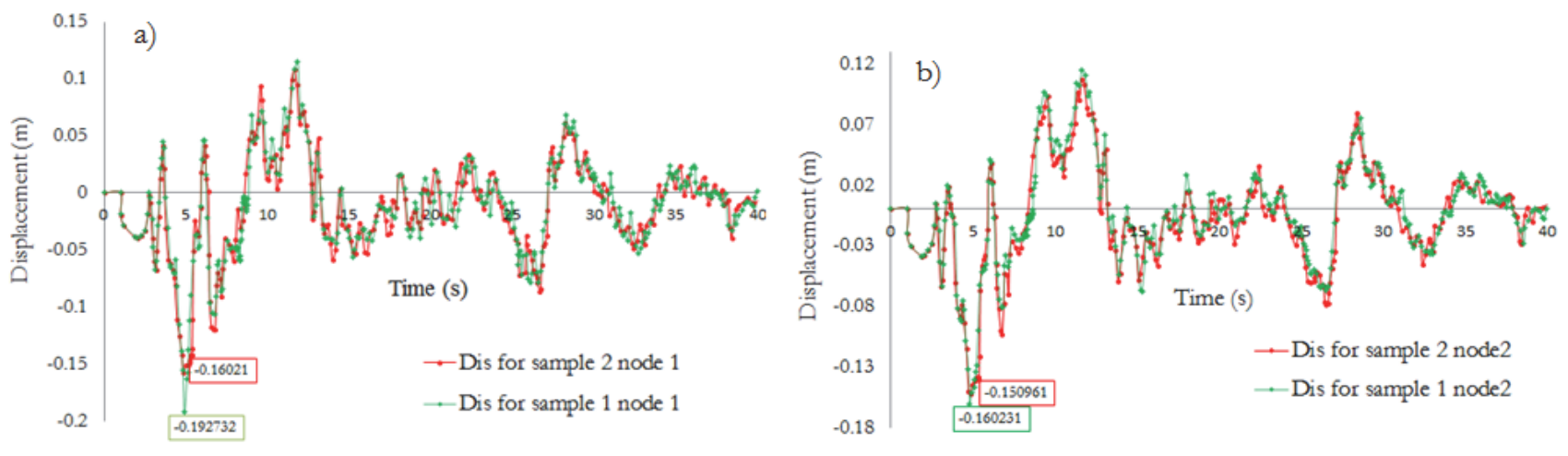

Figure 10: Displacement of the concrete layers (a) on the right side, b) on the left side)

Fig. 11 presents the frame displacement on the right and left sides of the building. Comparison of sample 1 with sample 2 shows that the displacement measure with sample 2 decreases by 1.2 times on the maximum value.
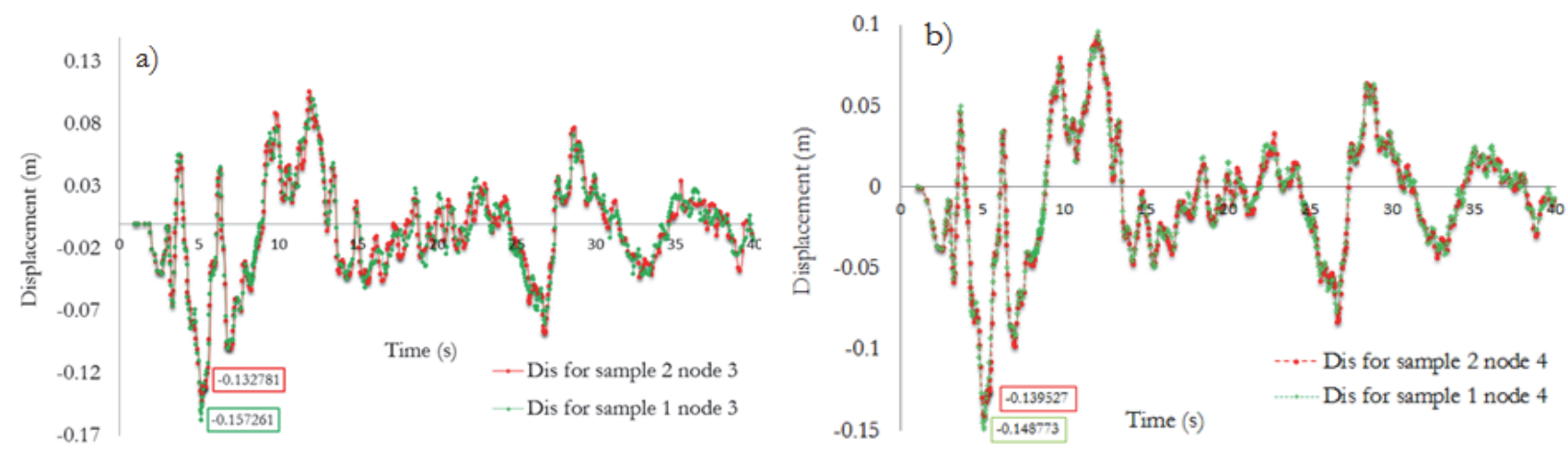

Figure 11: Displacement of the building frame (a) on the right side, b) on the left side) 
Fig. 12 shows that the displacement in the insulating layer having low density and height has the lowest displacement in the frame. According to Fig. 12, the insulating layer displacement on the right side of the panel is approximately similar. On the left, increasing the number of sandwich panels increases the frame displacement measure.
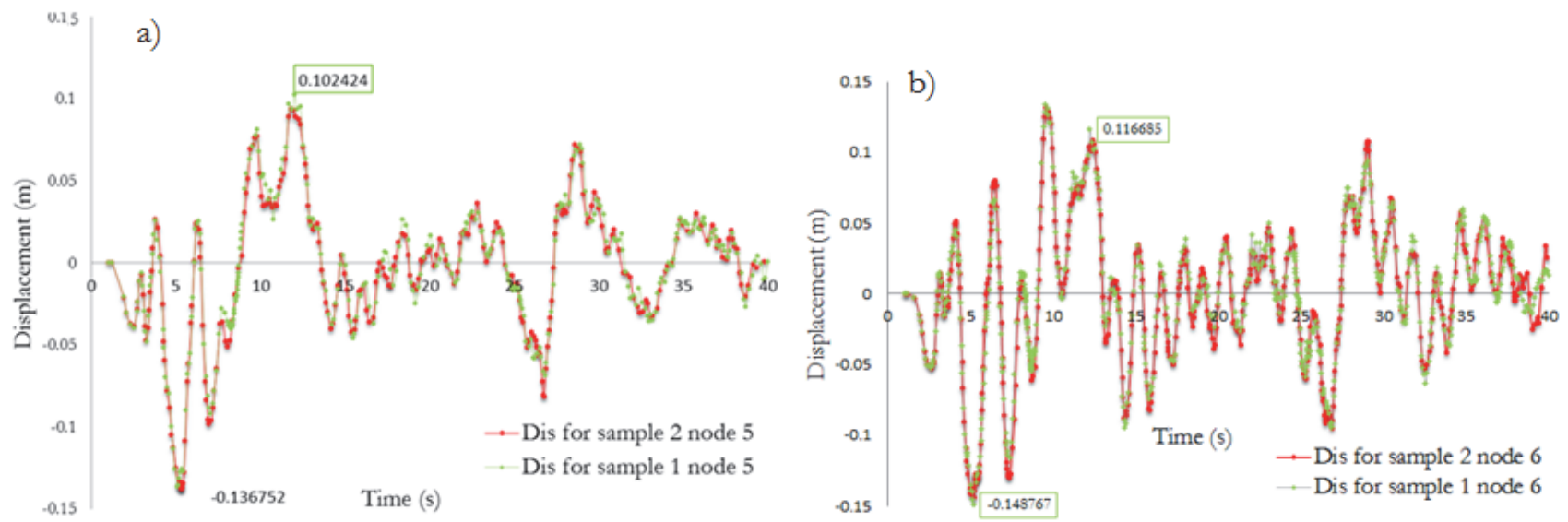

Figure 12: The polystyrene panel displacement (a) on the right side, b) on the left side).
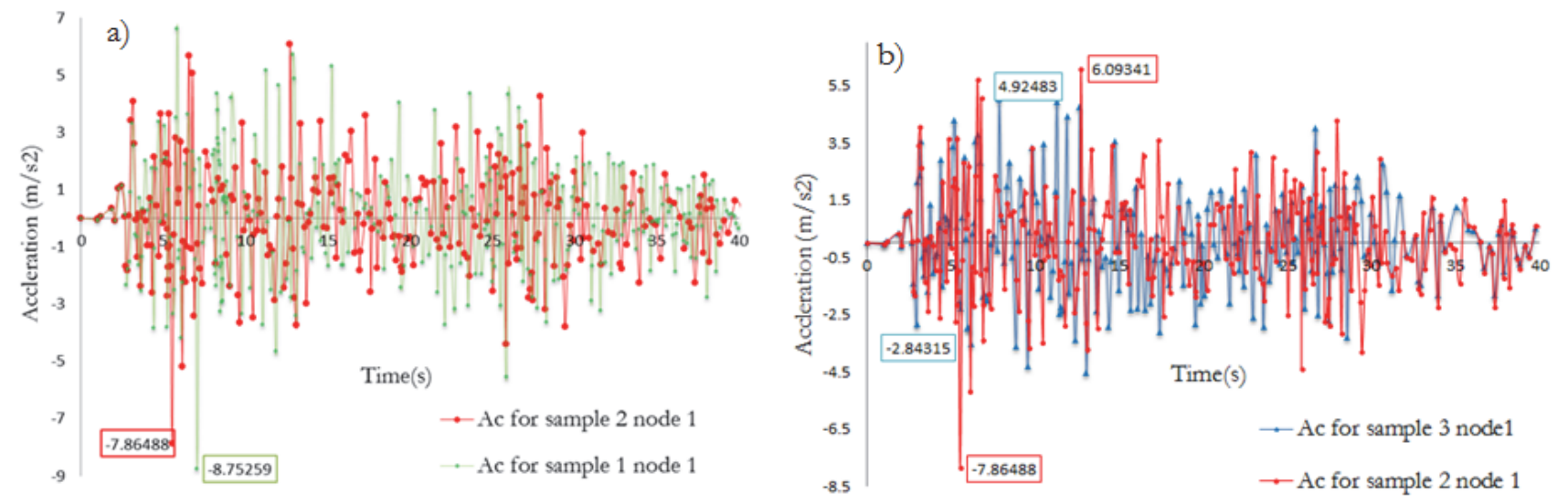

Figure 13: The acceleration on the left side of the concrete layers (a) sample 1 and 2, b) sample 2\&3).
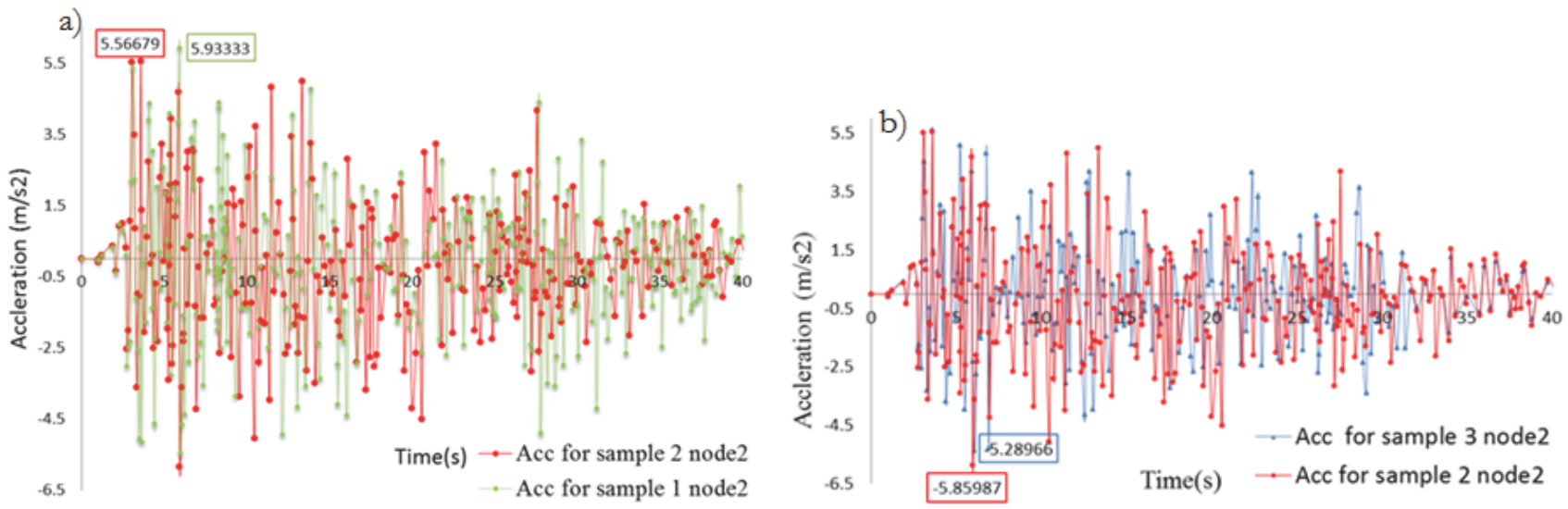

Figure 14: The acceleration on the left side of the concrete layers (a) sample 1 and 2, b) sample 2\&3). 

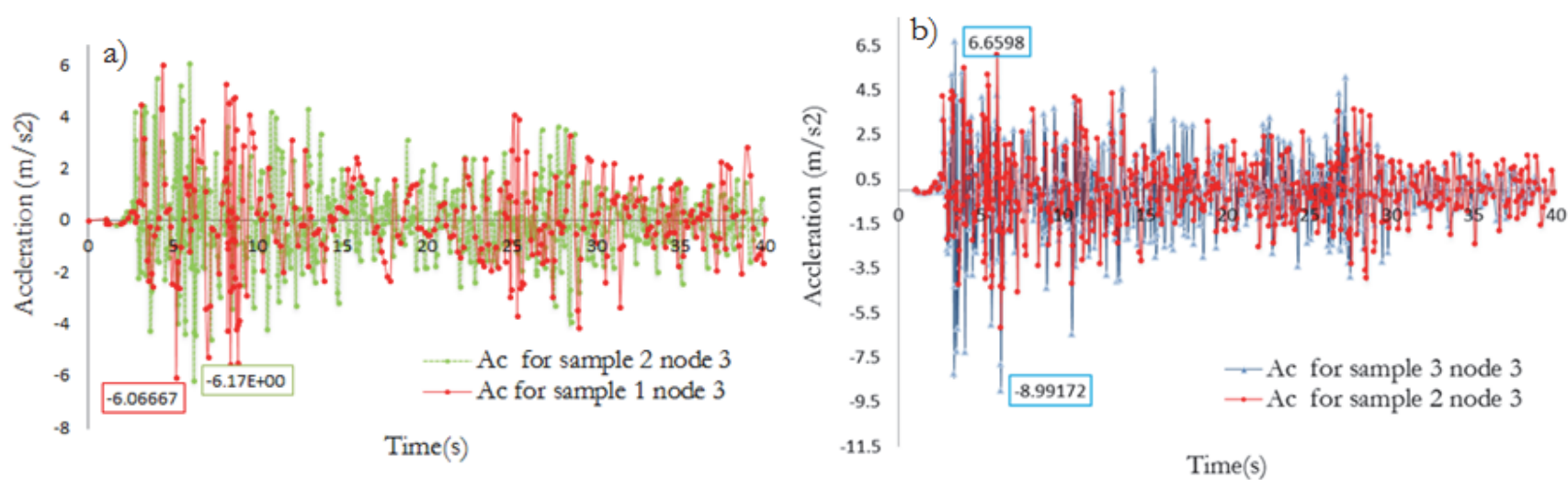

Figure 15: The acceleration on the right side of the steel frame (a) sample 1 and 2, b) sample2\& 3).

Figures 13 -16 show the acceleration imparted to the building for the three kinds of concrete. Using shotcrete with high Young's modulus increases the building resistance against lateral load. Acceleration in the concrete layers of higher Young's modulus is more uniform and evenly distributed over all the building panels. Comparing the two shapes with each other shows that using sandwich panels with Silica additive (increasing the Young's modulus) improves the seismic behavior of a building.
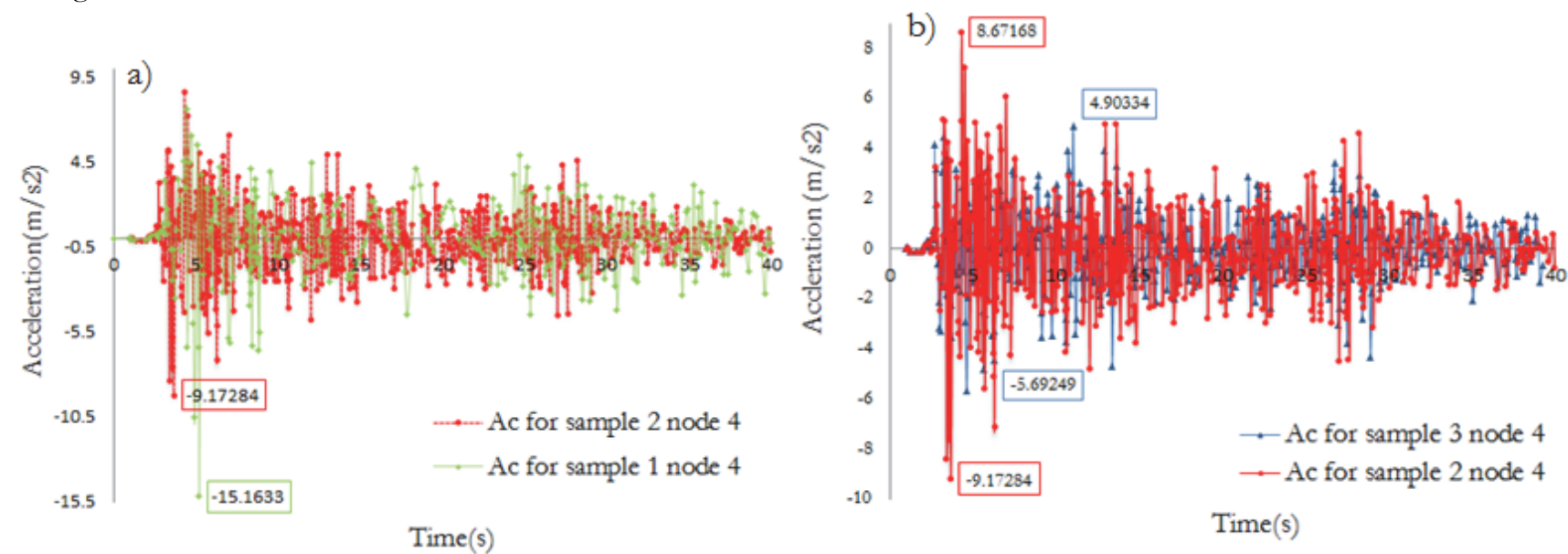

Figure 16: The acceleration on the left side of the steel frame (a) sample 1 and 2, b) sample $2 \& 3$ )

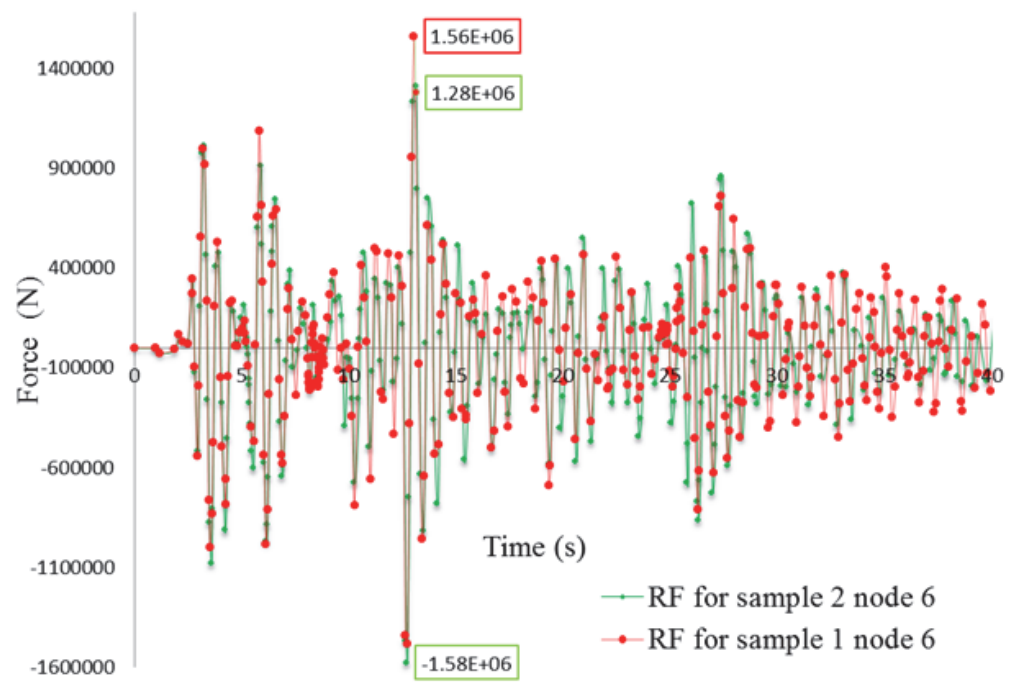

Figure 17: The base shear measure for point 7. 
Fig. 17 presents the base shear in the panel corner. The results of the three modes show that the base shear for the first sample (24-hours concrete) is higher than the other samples.

\section{THE RESULTS IN THE (Y) DIRECTION}

$\mathrm{I}$ $\mathrm{n}$ the following section, the displacement measure in the $\mathrm{Y}$ direction is discussed and the displacement results are presented in Fig. 18. As it is clear along the $\mathrm{X}$ direction, for all cases, the displacement measure on the right side (concrete layers, steel frame, and insulating layers) is greater than that on the left side. As a result, it is recommended that for applying the panels in the both directions, shotcrete with high Young's modulus be used to control the displacement measure. In addition, applying insulating layers and changing their material can improve the behavior of the frame in the $\mathrm{Y}$ direction. Fig. 18 depicts the displacement measure of the concrete layers on the right side.

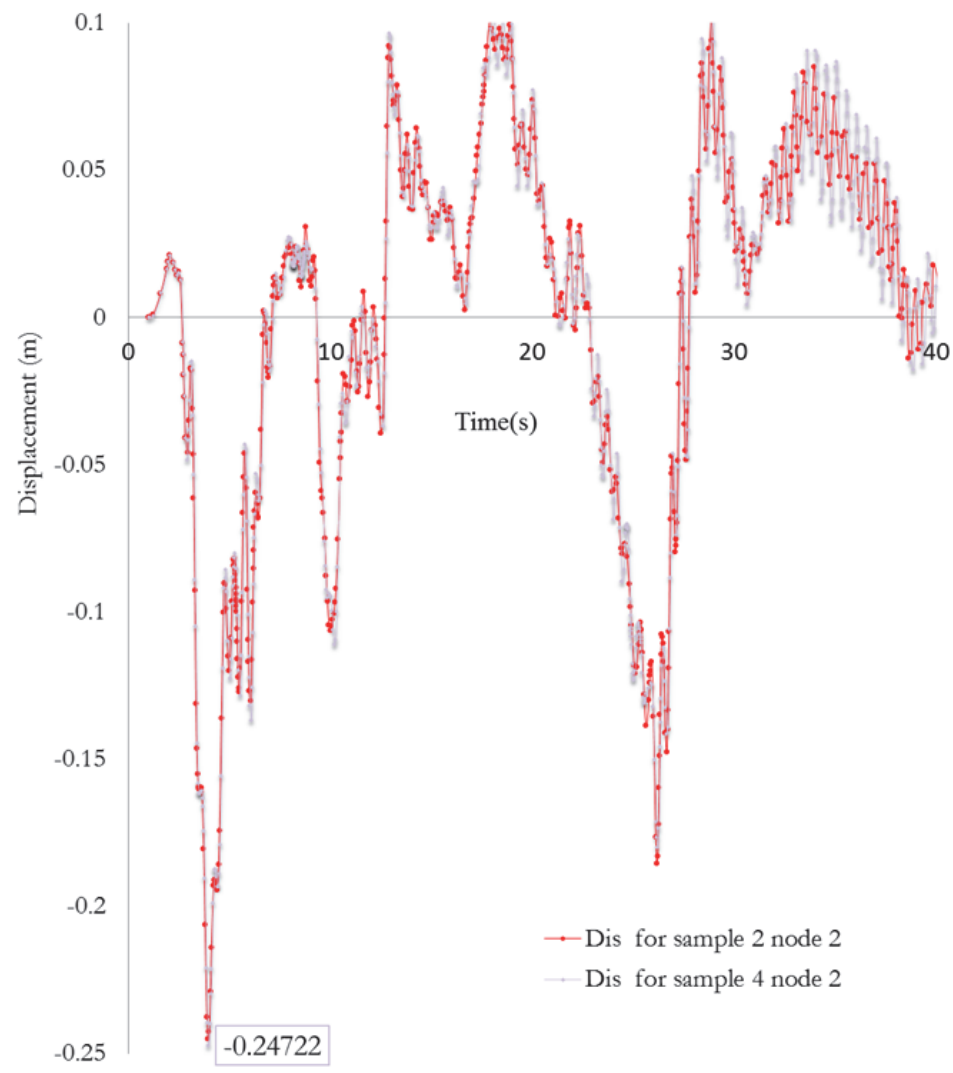

Figure 18: The concrete layer displacement in the $\mathrm{Y}$ direction

\section{HYSTERESIS CYCLE}

$\Lambda$ pplying the insulating layer between the concrete layers makes the sandwich panels efficient in damping energy. The hysteresis cycles are regular in all cases. The output analysis for the 63- day concrete and 24-hour concrete shows that increasing the Young's modulus makes the hysteresis cycle more regular. Therefore, it seems that applying shotcrete concretes with high Young's modulus improves the behavior of sandwich panels. In addition, it significantly affects the frame performance, decreases its displacement and acceleration measures. Comparing the sample shown in Fig. 19 indicates that the energy dissipation in sandwich panels with shotcrete has acceptable performance when compared to brick material; the tolerance between maximum and minimum value of displacement and force is increased in the brick material. Generally, the bigger areas below the graphs represent higher energy absorption as well as more ductile behavior of the structural element. Sample 1 and brick layers effort to store most of seismic load (higher area) and have higher energy absorption by the system, because of more crack initiation in the concrete with lower Young's modulus and brick panels. As loading cycles increase, the rigidity of system would decrease gradually; this was indicated by the last cycles slope. The positive relationship between starting crack and absorbing seismic load has been proved by Rezayifar, too [8]. 
a)

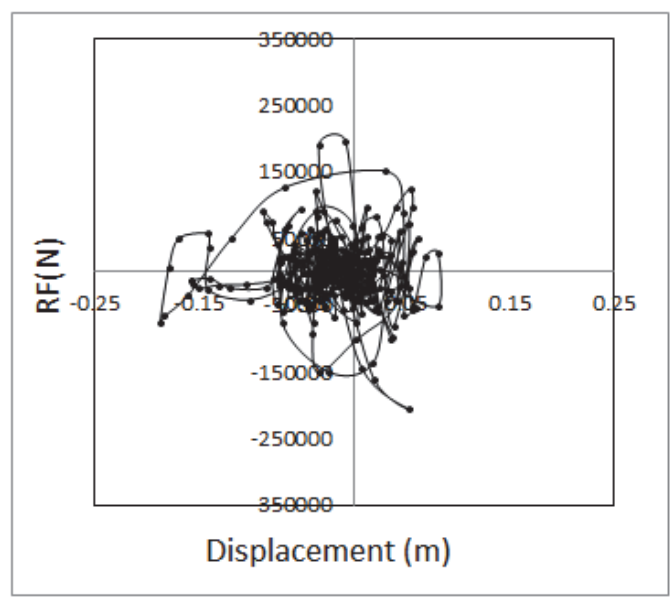

c)

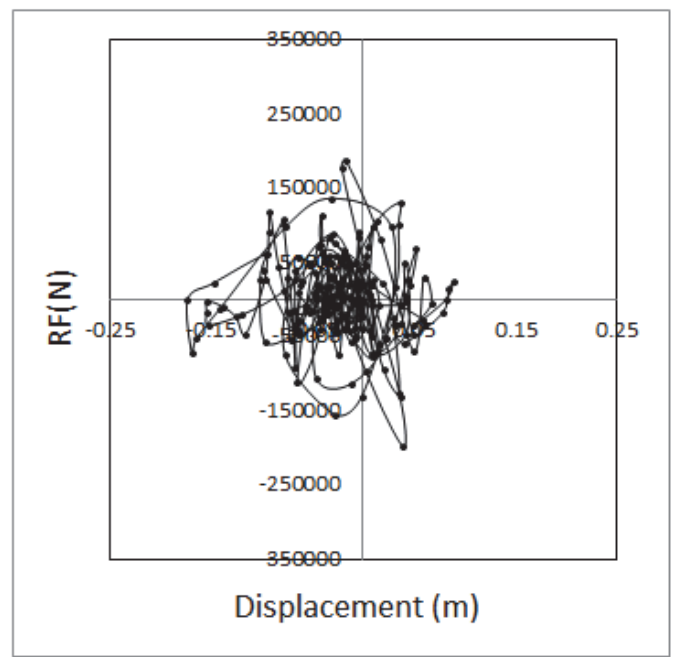

b)

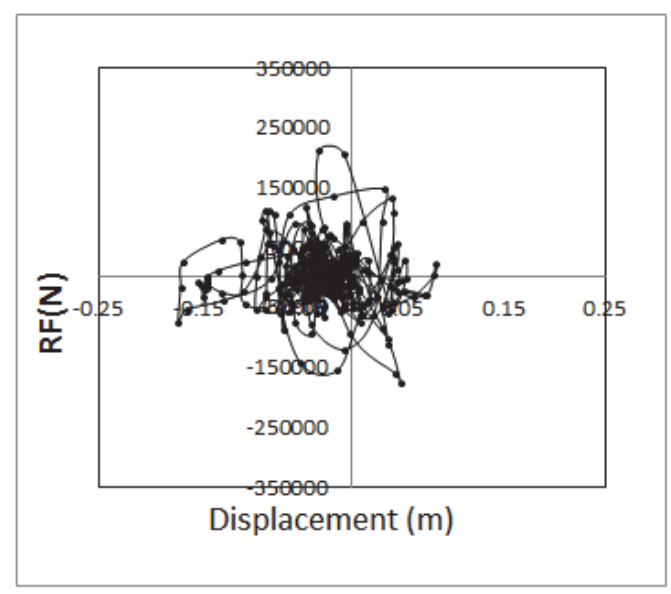

d)

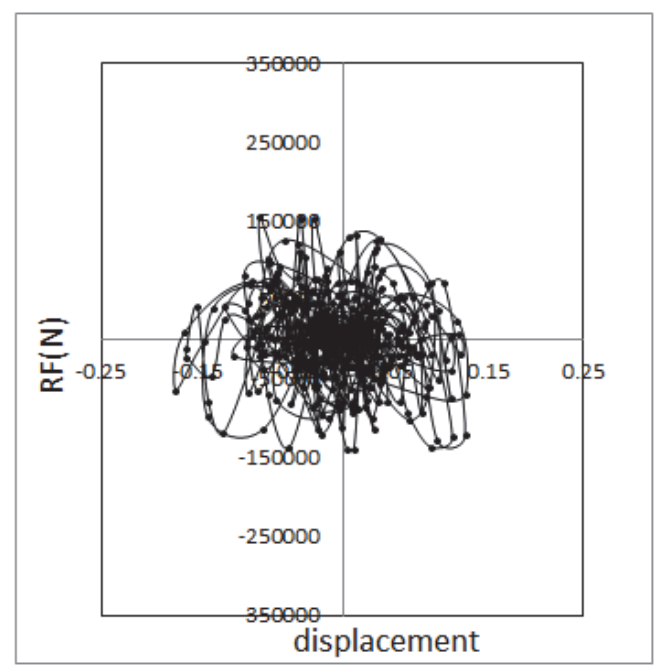

Figure 19: The hysteresis loops for different samples (RF for node 7 and displacement for node 1) (a) sample 1, b) sample 2, c) sample 3, d) sample 4).

\section{RSM VALUES}

$\mathrm{U}$

ltimately, the results have been obtained and presented in Fig.20 and 21 for displacement and acceleration. The displacement and acceleration were decreased on the concrete layers with utilizing 63-day concrete and 7-day concrete, the displacement measure on the brick wall was 1.76 times more than that on the sandwich panel with 63 days.

The square value of displacement and acceleration data has been calculated for each interval ( 0 - 40 seconds), the average extracted for each point (1-6) in each sample, and then the square root obtained from this value (RSM). These values were then compared with sample 4 and called a ratio.

$$
\text { Ratio } \frac{\operatorname{RSM}(1,2 \text { or } 3)}{\operatorname{RSM}(4)}=\frac{\sqrt{\text { average }(\text { square }(\text { displacement and acceleration of sample } 1,2,3))}}{\sqrt{\text { average }(\text { square }(\text { displacement and acceleration of sample } 4))}}
$$




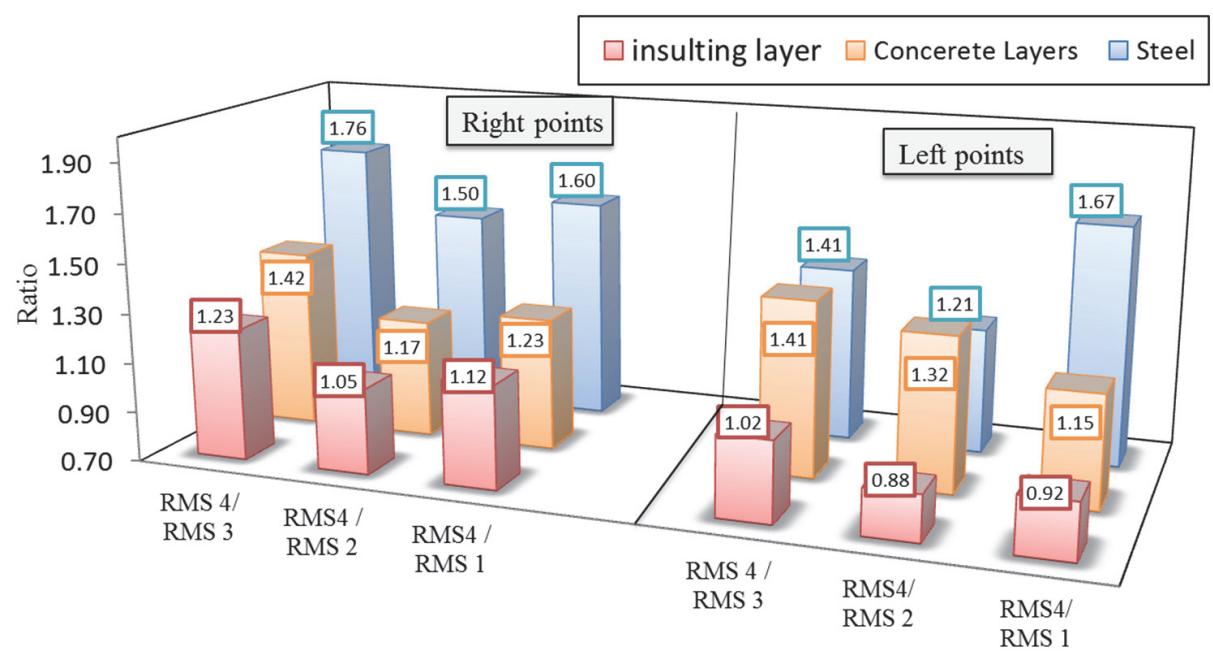

Ratio For RSM Displacement

Figure 20: RMS ratio for displacement between different samples.

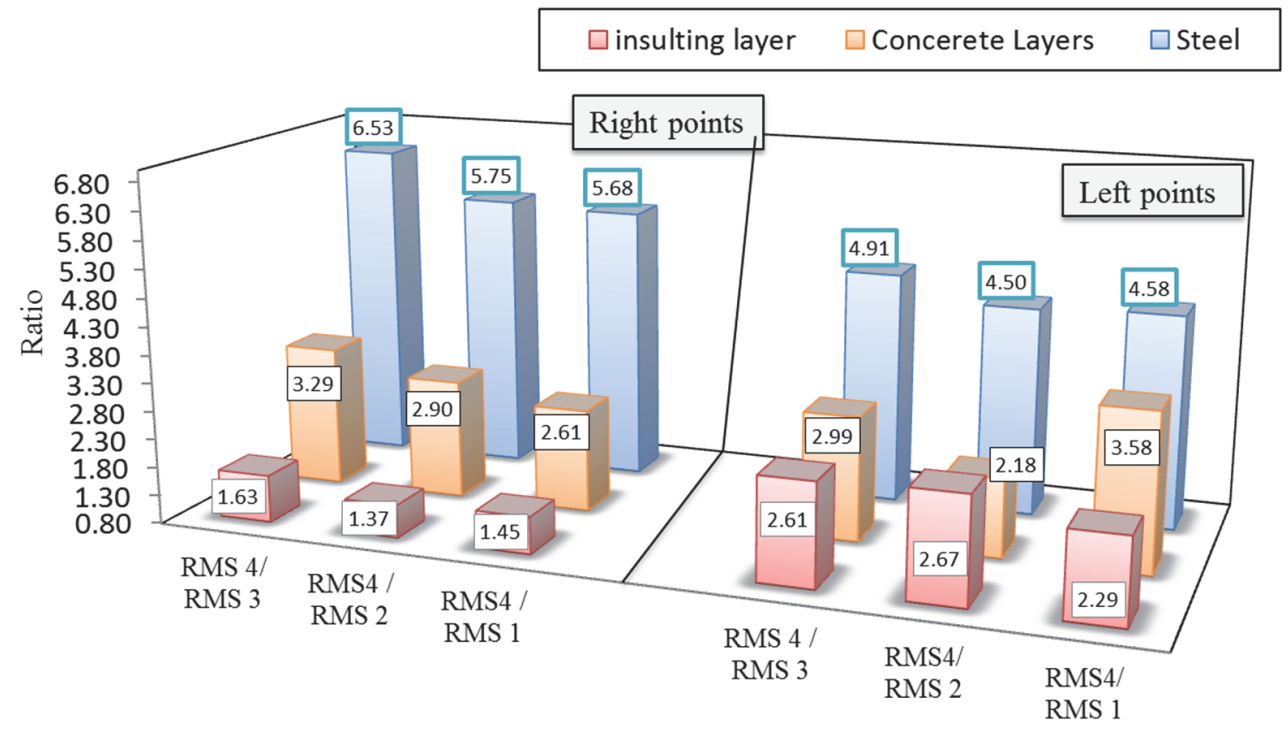

Ratio for RSM Acceleration

Figure 21: RMS ratio for acceleration between different samples

\section{USING ANFIS AS A NEURAL NETWORK TO DISCUSS ON THE RESULTS}

A $\mathrm{n}$ adaptive neuro-fuzzy inference system is categorized as artificial neural network, which is based on Takagi-Sugeno fuzzy inference system, and its initial application was in the early 1990s. This technique employed both neural networks and fuzzy logic principles in order to use approximate nonlinear functions. To describe the architecture of an ANFIS, the first order Sugeno-style FIS is introduced. A first-order Sugeno-style FIS model is a system that manages the process of mapping from a given crisp input to a crisp output, using fuzzy set theory [28]. Using ANFIS, as a method for discussing the result of this study, is a new method to analyze the output of ABAQUS. Fig. 22 indicates the structure of ANFIS. This ANFIS network has been built in three layers namely the input layer, hidden layers, and output layer. Each layer consists of one or more nodes, depicted by the small circles in Fig. 22. The arrows between different nodes introduce the classified information which flows from one node to the next. Height, the numbers of panels, Young's modulus, and the time have been assumed as input layers, while displacement and acceleration have been considered as the output values. 


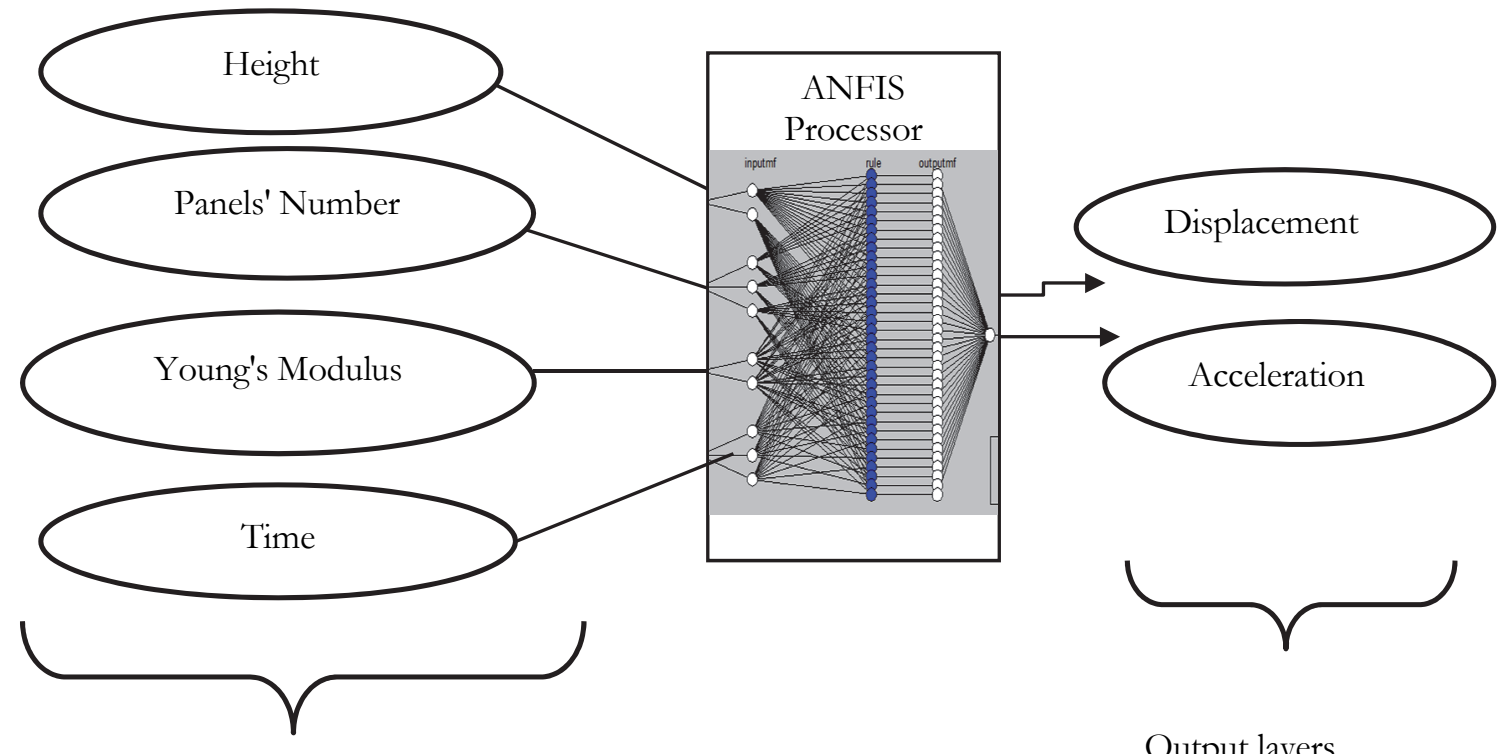

Figure 22: ANFIS structure for prediction.

In this study, correlation coefficient $\left(\mathrm{R}^{2}\right)$ and root mean square error (RMSE) were obtained to show accuracy of ANFIS models. Different studies use these parameters to evaluate the efficiency of neural network models [29-31].

\section{ANFIS VERIFICATION}

$\mathrm{F}$ or this purpose, 8 points were added to the middle and ceiling of each panel: four on the left and four on the right side of the building. The absolute value of displacement and acceleration for 31 seconds was extracted from ABAQUS simulation for each point (points 1-6 and these 8 points) and finally, the maximum value for each 8 seconds at all points was obtained. Height, panels' number, Young's modulus and time were chosen as an input layer and the value of the displacements and accelerations were assumed as an output layer. Finally, the value of the output layers was predicted with MATLAB -ANFIS GUI. The 3-D surface plot shows the variation of the accelerations and displacements for four buildings (brick material, 3 samples of different concrete). The number of data was 187; one fourth of these data was assumed for validating and one fourth was used for testing and the remaining used in the training process. Hybrid FIS with 11 epochs were used to predict acceleration. The number of age bell membership function was obtained and hybrid function again was used and the MF numbers were 2,6,3,3 for each input layer. Using the above process for displacement, the function type obtained trap membership function and the MF numbers were assumed 2,3,3,4. The results show that the values obtained from the ANFIS model are very close to the FEM results and the $\mathrm{R}^{2}$ value is nearly 0.94 for displacement and 0.9 for acceleration.

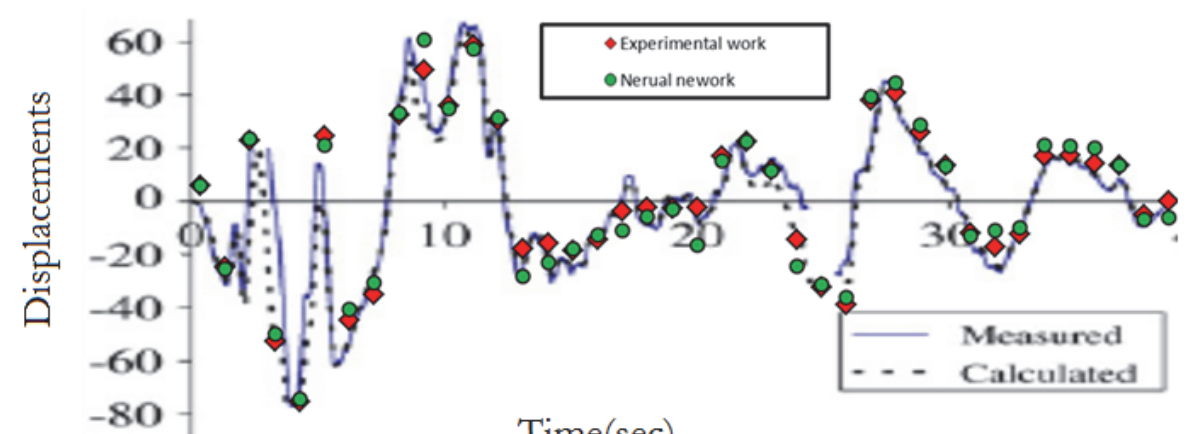

Time(sec)

Figure 23: ANFIS result for verification model. 
In this paper, the extent of displacement obtained by ANFIS was explored for model verification, which has been compared with experimental model [8]. Fig. 23 reveals the extent of maximum displacement for every three seconds, which has been obtained by ANFIS model. This was compared with the values obtained from experimental paper. The results suggest that ANFIS can predict the maximum values close to experimental results. $\mathrm{R}^{2}$ value is nearly 0.97 for these data and the RMSE value is 0.0000427 .

\section{USING ANFIS FOR DISCUSS THE DISPLACEMENTS AND ACCELERATIONS}

A fter confirming the performance and capability of FIS models, the variation of the displacements and accelerations of all FEM models was examined as output surface, which was obtained by the fuzzy inference system.

Figs. 24 and 25 present the variation of the displacements and accelerations for 14 points. These Figures show the relationship between input variable (height, Young's modulus, panels' number and times) on the output layers. It shows how these two input factors can influence the output layers in a different building.

Figs. 24 and 25(a) show that decreasing the panels' number and time decreases the displacement and acceleration variation. These two factors directly influence displacement. Based on this figure, the displacement variation when the panels' number is two is higher than when the panels' number is 3 . The surface variation is also related to the time, as the surface is more variable when the time is less than 20 seconds. The acceleration variation depends on the panels' number and time too, as this surface is more variable when the panels' number is 3. For three panels, the maximum variation occurred when the time is less than 15 seconds, maximum Electro acceleration is related to this time, and this variation is more obvious at three panels for acceleration.

Figs. 24 and 25(b) show that increasing the value of the Young's modulus decreases the acceleration variation during the time. It is clear from the 2-D figures that in the brick material, the RMS is greater than others and the displacements are not damped but are reduced during the time; however, the value of displacements and also accelerations for sample 3 are strongly reduced when time passes 12 seconds.

Figs. 24 and 25(c) demonstrate the variation of displacement and acceleration related to the height and the panels' number. These figures show that the maximum variation of displacement and acceleration is related to three panels and the surface variation increases when the height reaches six meters. The surface variation is more variable when the panels' number is 3 and with increasing height this variation increases.

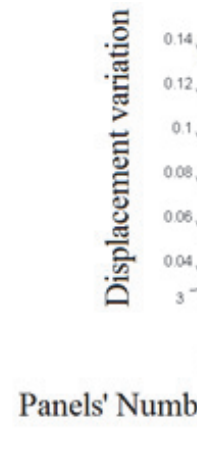

a)

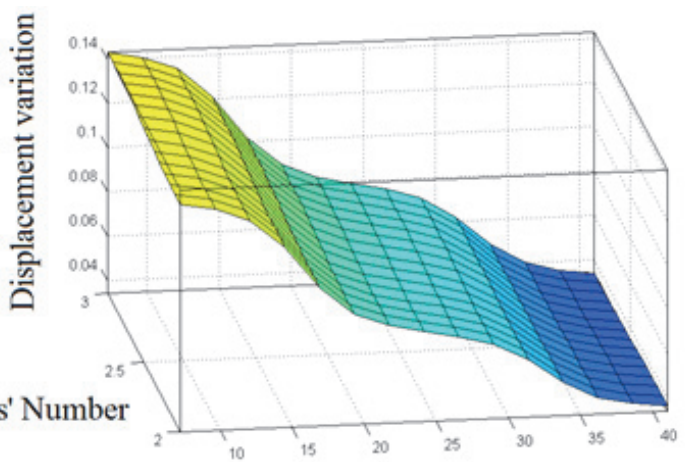

Time (s)

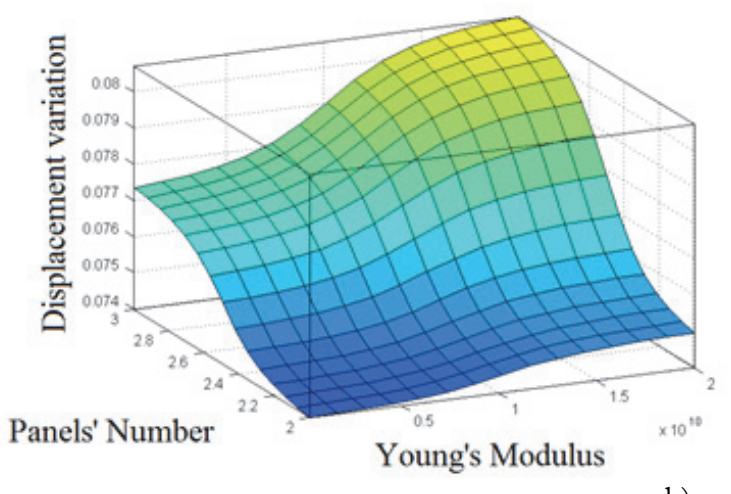

b)

Panels' Number

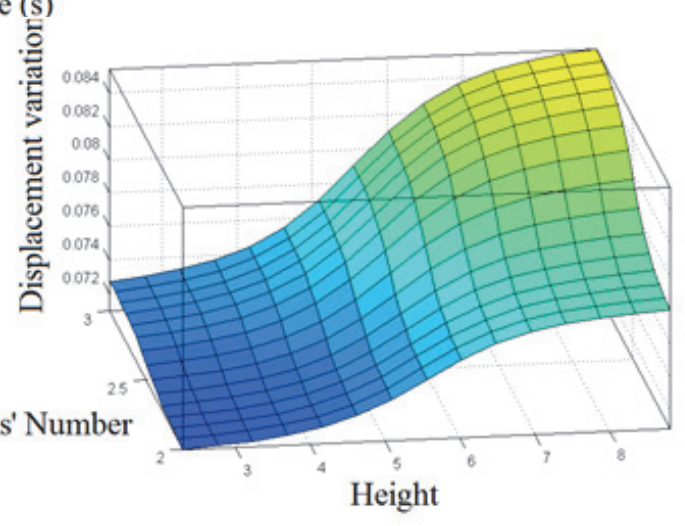

Figure 24: Predict the variation of the displacement surface with ANFIS 

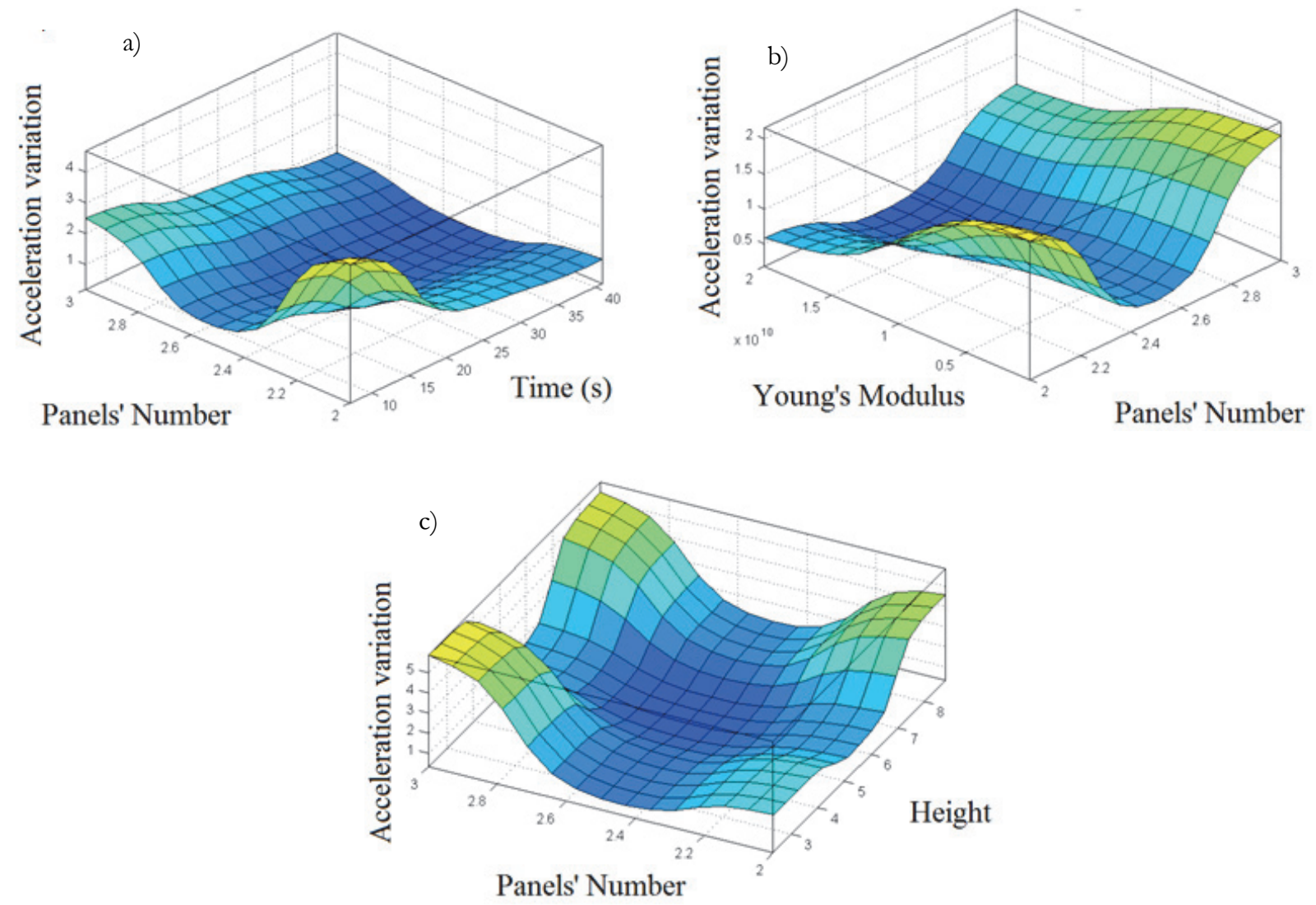

Figure 25: Predict the variation of the acceleration surface with ANFIS

\section{DISCUSSION}

$\mathrm{N}$ umerical modeling of the sandwich panels and changing the applied shotcrete material, which have not been studied so far, were investigated in the present study. The shotcrete and the change in its Young's modulus affected the building behavior in a manner that great changes were observed in the displacement and acceleration of the panels, frames, and concrete layers. Investigating the 63 day, 7 day and 24 hour concretes and comparing the results show that the age of the concrete can affect the building behavior. In all cases, the wires showed good reaction against the earthquake load and no one was separated from the concrete. Using the diagrams of force, displacement, acceleration and hysteresis cycle, the present research investigated the panel behavior. By changing sandwich panels' number on the two sides of the frame, this study evaluated the frame maximum deflection under the Elcentro-1940 record. One of the issues of the research was the high simulation time, due to choosing solid elements for all the components (except for the wires). Using ANFIS to elaborate and predict the result of FEM is an innovation of this paper for discussing the building performance. The computations of the application of sandwich panels in the frame instead of brick material demonstrated that the building weight decreases according to Tab. 3.

\begin{tabular}{cccc}
\hline Point & & \\
Material & Weight $(\mathrm{kg})$ & Total volume $\left(\mathrm{m}^{3}\right)$ & Total weight $(\mathrm{kg})$ \\
Normal brick & 14515.2 & 6.048 & 101606.4 \\
Total weight for sandwich & 11662.2 & 6.048 & 81637.4 \\
panel & 6654.8 & 3.024 & \\
Concrete & 4536 & 3.024 & \\
insulating layer & 473.4 & 0.06 & \\
Wire &
\end{tabular}

Table 3: Comparison of the weight of the building with brick and with sandwich panels. 
The result shows that total displacement $(\mathrm{U})$, acceleration as well as RSM value decrease with increment of Young's modules.

- Compared to building with brick panel, by increasing Young's modulus in sample (3), the total displacement (U) of the concrete panel (point 2) decrease by 0.33 and RSM ratio $\left(\frac{\operatorname{RSM}(\text { sample } 3)}{\operatorname{RSM}(\text { sample } 4)}\right)$ decrease by 0.71 . Moreover, as compared to sample 2, the overall displacement decreases by 0.92 and RSM decrease by 0.93 . The total acceleration $\left(\mathrm{A}_{\mathrm{t}}\right)$ decrease by $56 \%$ and RSM by 0.33 and these modules affects the reduction level of cyclic area, such that the area reduction is lower than $20 \%$ when using sample (3) as compared to the brick material wall. In addition, as compared to sample 2, the overall acceleration decreases by $86 \%$ and RSM decreases by 0.73 , however, the maximum accelerations ratio $\left(\frac{A \operatorname{cmax}(\text { sample } 3)}{A \max (\text { sample } 1)}\right)$ is 0.82 and RSM ratio is 1.17 . According to all above mentioned result, sample (3) has the best performance because it has the lowest displacement and acceleration under earth quake load.

- Compared to building with brick panel, with using sample 3, the total displacement (U) of the steel frame in the building (point 3) decreases by $67 \%$ and RSM decrease by $57 \%$. The total acceleration $\left(A_{t}\right)$ decrease by 0.21 and RSM by 0.15 . In addition, as compared to other case (sample 2), the overall displacement decreases by 0.97 and RSM decreases by 0.85 . Moreover, the overall acceleration ratio $\left(\frac{A \max (\text { sample } 3)}{A \max (\text { sample } 2)}\right)$ is 0.85 and RSM ratio is 0.88 .

- Compared to sample 4, the maximum of displacement $(\mathrm{U})$ of the insulting layers (point 5) decrease by 0.58 and RSM decreases by 0.81 in sample 3 ., the total acceleration $\left(A_{t}\right)$ decrease by 0.78 while RSM increases by 0.61 . Moreover, compared to sample 2, the ratio of maximum displacement $\left(\frac{\mathrm{Umax}(\text { sample } 3)}{\operatorname{Umax}(\text { sample } 2)}\right)$ is 0.84 and RSM ratio is 0.84 .

- The displacement of concrete panel increase in the right frame, the ratio of RSM displacement ( $\left.\frac{\text { URSM Left side }}{\text { URSM Right side }}\right)$ for displacement is 1.06 for sample 3, while this value is 1.20 for sample 2, 0 for sample1 and 1.06 for brick material. The same ratio for steel part is 1.03 for sample $3,1.04$ for sample and sample1, and 1.30 for brick material

- The acceleration of concrete panel increase in the right frame, the ratio of RSM $\left(\frac{\text { Left side }}{\text { Right side }}\right)$ for acceleration is 1.08 for sample 3, while this value is 1.223 for sample 2, 0 for sample1 and 1.06 for brick material .The same ratio for steel part is 1.32 for sample 3, 0.78 for sample and sample1, and $74 \%$ for brick material.

- Neural network method was employed in this study final step; this research purpose was to evaluate the capability of using ANFIS for estimating the displacement and acceleration magnitude. Using ABAQUS in order to analyze the concrete solid material is considered as a time consuming method, due to the fact that concrete panels were model with concrete damage plasticity technique. In this study, the analysis of each model was completed by passing 48 hours. It is clear that using super computer can reduce this time, but this computer accessibility is not easy for all engineering. This study results indicates that the ANFIS is able to predict the FEM results, and also the displacement and acceleration magnitude, which were obtained with ANFIS models and were close to FEM result. Hence, applying ANFIS can help engineering to attain the building performance under the earthquake condition without the use of laboratory test or FEM software.

\section{CONCLUSION}

$\mathrm{S}$ andwich panels have been widely used in the building construction industry. Improving the sandwich panel behaviors is studied in different researches and different analysis methods are considered. Using additives to improve the shotcrete concrete and concrete has been the subject of various studies. The literature on improving the panel behavior shows that using Silica in concrete is possible and easy to execute. Improving the compressive, tensile, and bending resistance of concrete has been extensively studied, but there is no research available on enhancing the lateral resistance in 
the building. However, there is a lack of numerical investigations for elaborating the effect of shotcrete sandwich panel and its performance improvement on earthquake load in the steel building. This paper combined two methods (FEM and

ANFIS) for analyzing sandwich panel in the building. The present study has the following conclusions:

- The frame weight decreases while the design decreases its displacement and the acceleration. One way of decreasing the building weight is to use sandwich panels instead of ordinary walls. In this research, the walls of brick material were compared with sandwich panels. The panel displacement and the acceleration were significantly decreased in the panels with shotcrete.

- According to the diagrams, changing the shotcrete material (improved Young's modulus) decreases the response value of the frame, the concrete layers, and the displacement and acceleration of the insulating walls (the core).

- Different points were considered in the frame and the displacement and acceleration measures were evaluated. Using Polystyrene insulating layer decreases the frame displacement. Since the core volume is twice the concrete layers volume and it is invariable in different models, more variation for displacements and acceleration was observed in the concrete layers diagrams; these layers have a significant effect on decreasing the displacements and acceleration of the frame.

- Using the properties of ordinary brick instead of concrete and keeping other parameters such as shape and size of the building unchanged leads to an increase in displacement and acceleration.

- Studying the displacements of 24-hour concrete and 63-day concrete shows that decreasing the Young's modulus led to more variation of the displacement and acceleration in all of the building panels. While in brick material, the maximum displacement measure occurs in the steel frame and the displacement is not damped in the building members (steel frame and concrete). Due to similar density of concrete in all the panels and models, increasing the Young's modulus improves the concrete panel behavior.

- It is concluded that whatever decreases the panel core and the shotcrete layers density and increases their Young's modulus results in better seismic behavior of the sandwich panels.

- ANFIS method, as a predictable method, has a good performance; this method can predict FEM result. In addition, it is able to elaborate the variation of displacement and acceleration. It is noteworthy that the amount of displacement and acceleration, which has been obtained with ANFIS, is very close to FEM.

\section{REFERENCES}

[1] Shehata, M. and Klement, T. (2005). Curing silica fume shotcrete with wet-sprayed cellulose. Shotcrete.ASA.

[2] Wolsiefer Sr, J. and Morgan, D. R. (1993). Silica fume in shotcrete. Concrete International, 15(4).

[3] Metelli, G., Bettini, N. and Plizzari, G. (2011). Experimental and numerical studies on the behaviour of concrete sandwich panels. European Journal of Environmental and Civil Engineering, 15(10), pp. 1465-1481.

[4] DOI: 10.1080/19648189.2011.9723354

[5] Palermo, M., Ricci, I., Silvestri, S., Gasparini, G., Trombetti, T., Foti, D. and Ivorra, S. (2014). Preliminary interpretation of shaking-table response of a full-scale 3-storey building composed of thin reinforced concrete sandwich walls. Engineering Structures, 76, pp. 75-89. DOI: 10.1016/j.engstruct.2014.06.024.

[6] Yokozeki, T. and Iwamoto, K. (2016). Effects of core machining configuration on the debonding toughness of foam core sandwich panels. Advanced Composite Materials, 25(1), pp. 45-58. DOI: 10.1080/09243046.2014.958302.

[7] Hashemi, S. J., Razzaghi, J. and Moghadam, A. S. (2017). Behaviour of sandwich panel infilled steel frames with different interface conditions. Proceedings of the Institution of Civil Engineers-Structures and Buildings, pp. 1-12.

[8] Heywood, M. D., Ogden, R. G. and Moutaftsis, D. (2013). Profiled sandwich panels with deep foam cores in flexure. Proceedings of the Institution of Civil Engineers-Construction Materials, 167(1), pp. 42-56.

[9] Rezaifar, O., Kabir, M. Z. \& Tehranian, A. (2007). System Identification of Dynamic Behaviour of 4 Story Scaled 3D Panel Building Using Shaking Table, ASCE Journal of Structural Engineering. DOI: 10.1016/j.engstruct.2007.03.019.

[10] Palermo, M. and Trombetti, T. (2016). Experimentally-validated modelling of thin RC sandwich walls subjected to seismic loads. Engineering Structures, 119, pp. 95-109.

[11] Lee, J. J. and Yun, C. B. (2007). Damage localization for bridges using probabilistic neural networks. KSCE Journal of civil engineering, 11(2), pp. 111-120. DOI: 10.1007/BF02823854.

[12] Arslan, M. H. (2012). Estimation of curvature and displacement ductility in reinforced concrete buildings. KSCE Journal of Civil Engineering, 16(5), pp. 759-770. DOI: 10.1007/s12205-012-09581. 
[13] Bagheri, A., Amiri, G. G. and Haghdoust, J. (2014). New method for the estimation of strong ground motions based on the colonial competitive algorithm. KSCE Journal of Civil Engineering, 18(5), pp. 1403-1410.

DOI:10.1007/s12205-014-0034-0.

[14] Pang, Y., Dang, X.and Yuan, W. (2014). An artificial neural network based method for seismic fragility analysis of highway bridges. Advances in Structural Engineering, 17(3), pp. 413-428.

[15] Kalman Šipoš, T.and Strukar, K. (2019). Prediction of the Seismic Response of Multi-Storey Multi-Bay Masonry Infilled Frames Using Artificial Neural Networks and a Bilinear Approximation. Buildings, 9(5), 121.

[16] Gholizadeh, S. and Salajegheh, E. (2010). Optimal design of structures for earthquake loading by self organizing radial basis function neural networks. Advances in Structural Engineering, 13(2), pp. 339-356.

[17] Badarloo, B. and Jafari, F. (2018). A Numerical Study on the Effect of Position and Number of Openings on the Performance of Composite Steel Shear Walls. Buildings, 8(9), 121.

[18] ABAQUS Version 13 (General Purpose Finite Element Analysis Software documentation).

[19] Gara, F., Ragni, L., Roia, D. and Dezi, L. (2012). Experimental behavior and numerical analysis of floor sandwich panels. Engineering Structures, 36, pp. 258-269. DOI: 10.1016/j.engstruct.2011.12.011.

[20] Center, P. E. E. R. (2013). Peer ground motion database. Pacific Earthquake Engineering Research Center, University of California, Berkeley, CA, http://ngawest2. berkeley. edu.

[21] ACI Committee. (2005). Building code requirements for structural concrete (ACI 318-05) and commentary (ACI 318R05). American Concrete Institute. DOI: 10.14359/12026.

[22] Hsu, L. S. and Hsu, C. T. (1994). Complete stress-strain behaviour of high-strength concrete under compression. Magazine of Concrete Research, 46(169), pp. 301-312.

[23] Popovics, S. (1998). Strength and related properties of concrete: A quantitative approach. John Wiley \& Sons.

[24] Nilson, A. H. and Martinez, S. (1986). Mechanical properties of high-strength lightweight concrete. In Journal Proceedings 83(4), pp. 606-613.

[25] Dufour, J. F., Reny, S. and Vézina, D. (2006). State-of-the-Art Specifications for Shotcrete Rehabilitation Projects.Shotcrete Magazine, 8(4), pp. 4-11.

[26] Kaushik, H. B., Rai, D. C. and Jain, S. K. (2007). Stress-strain characteristics of clay brick masonry under uniaxial compression. Journal of materials in Civil Engineering, 19(9), pp. 728-739.

[27] George, T., Deshpande, V. S., Sharp, K. and Wadley, H. N. (2014). Hybrid core carbon fiber composite sandwich panels: fabrication and mechanical response. Composite Structures, 108, pp. 696-710.

[28] ASTM (2000). 578-Standard Specification for Rigid. Cellular Polystyrene Thermal Insulation.

[29] Jang, J. S. (1993). ANFIS: adaptive-network-based fuzzy inference system. IEEE transactions on systems, man, and cybernetics, 23(3), pp. 665-685. DOI: 10.1109/21.256541.

[30] Ghanei, A., Jafari, F., Khotbehsara, M. M., Mohseni, E., Tang, W. and Cui, H. (2017). Effect of nano-CuO on engineering and microstructure properties of fibre-reinforced mortars incorporating metakaolin: experimental and numerical studies. Materials, 10(10), 1215.

[31] Naseri, F., Jafari, F., Mohseni, E., Tang, W., Feizbakhsh, A. and Khatibinia, M. (2017). Experimental observations and SVM-based prediction of properties of polypropylene fibres reinforced self-compacting composites incorporating nanoCuO. Construction and Building Materials, 143, pp. 589-598.

[32] Khotbehsara, M.M.; Miyandehi, B.M., Naseri, F., Ozbakkaloglu, T., Jafari, F., Mohseni, E. (2018). Effect of SnO $\mathrm{Sn}_{2}$ ZrO and $\mathrm{CaCO}_{3}$ nanoparticles on water transport and durability properties of self-compacting mortar containing fly ash: Experimental observations and ANFIS predictions. Constr. Build. Mater. 158, pp. 823-834. 